\title{
Daily fluctuations in young children's persistence
}

Julia A. Leonard ${ }^{1,2 *}$, David M. Lydon-Staley ${ }^{3,4,5}$, Sophie D. S. Sharp ${ }^{1}$, Hunter Z. Liu ${ }^{1}$, Anne T. Park ${ }^{1}$, Danielle S. Bassett ${ }^{4,5,6,7,8,9,10}$, Angela L. Duckworth ${ }^{1} \&$ Allyson P. Mackey ${ }^{1}$

${ }^{1}$ Department of Psychology, University of Pennsylvania, Philadelphia, PA 19104 USA

${ }^{2}$ Department of Psychology, Yale University, New Haven, CT, 06511 USA

${ }^{3}$ Annenberg School for Communication, University of Pennsylvania, Philadelphia, PA 19104 USA

${ }^{4}$ Department of Bioengineering, School of Engineering \& Applied Science, University of Pennsylvania, Philadelphia, PA 19104 USA

${ }^{5}$ Leonard Davis Institute of Health Economics, University of Pennsylvania, Philadelphia, PA 19104 USA ${ }^{6}$ Department of Electrical \& Systems Engineering, School of Engineering \& Applied Science, University of Pennsylvania, Philadelphia, PA 19104 USA

${ }^{7}$ Department of Neurology, Perelman School of Medicine, University of Pennsylvania, Philadelphia, PA 19104 USA

${ }^{8}$ Department of Physics \& Astronomy, College of Arts \& Sciences, University of Pennsylvania, Philadelphia, PA 19104 USA

${ }^{9}$ Department of Psychiatry, Perelman School of Medicine, University of Pennsylvania, Philadelphia, PA 19104 USA

${ }^{10}$ Santa Fe Institute, Santa Fe, NM 87501 USA

*Corresponding author: Julia Leonard, email: julia.leonard@yale.edu

\section{Acknowledgements}

We thank Yoojin Han and Greer Bizell-Hatcher for help coding the data. We thank Sophie Bridgers for critical feedback.

\section{Author Contributions}

J. A. Leonard and A. P. Mackey designed the study and wrote the manuscript. J. A. Leonard analyzed the data under the supervision of A. P. Mackey and D.M. Lydon-Staley. J. A. Leonard, S.D.E. Sharp, and H.Z. Liu collected the data. D.M. Lydon-Staley, A.L. Duckworth, D.S. Bassett, and A. T. Park provided critical revisions. All authors approved the final version of the manuscript for submission.

\section{Funding}

This research was supported by a Jacobs Foundation Early Career Research Fellowship to A.P.M., NIDA (1R34DA050297-010) to A.P.M. and a University of Pennsylvania MindCORE Postdoctoral Fellowship to J.A.L.

\section{Competing interests}

The authors declare no competing interests

Data and code availability

All data, materials, and preregistrations will be available on the Open Science Framework after publication. 


\title{
FLUCTUATIONS IN PERSISTENCE
}

\begin{abstract}
Children's behavior changes from day to day, but the factors that contribute to its variability are understudied. We developed a novel repeated measures paradigm to study children's persistence by capitalizing on a task that children complete every day: toothbrushing $(\mathrm{N}=81 ; 48 \%$ female; $36-47$ months; 80\% white, 14\% Multiracial, 10\% Hispanic, 2\% Asian, 1\% Black; 1195 observations). Children brushed longer on days when their parents used more praise $(d=0.23)$ and less instruction $(d=-0.22)$. Sensitivity to mood, sleep, and parent stress varied across children, suggesting that identifying the factors that shape an individual child's persistence could lead to personalized interventions.
\end{abstract}

Keywords: Motivation, intensive repeated measures, persistence, early childhood, intraindividual, parenting 


\section{FLUCTUATIONS IN PERSISTENCE}

To become healthy and successful adults, children need to persist on tasks that are not always easy or fun, like studying, exercising, or brushing one's teeth (Duckworth et al., 2007; Mischel et al., 1989). Children's ability to persist develops gradually (Oeri \& Roebers, 2020; Saudino et al., 1996; Zhou et al., 2007). Toddlers are notoriously strong-willed and easily distracted; yet just a few years later, they are expected to persist through challenging tasks like learning to read. Development is not always linear: children have good days where they easily persist through tasks, and bad days where they struggle to complete tasks they could do easily the day before. Understanding the psychosocial and physiological factors that shape within-child variability in young children's persistence is critical for developing personalized interventions to help children be the best versions of themselves.

In the present study, we measured fluctuations in three-year-olds' persistence by capitalizing on an ecologically-valid daily task that three-year-olds are just learning to do on their own: brushing their teeth. Toothbrushing is the ideal task because it is a daily behavior that parents want to support, and requires persisting on a task that is not especially fun, but is necessary for the development of a healthy habit. Toothbrushing is also not cognitively challenging, so individual differences in brushing are unlikely to be related to IQ. In other words, variation in toothbrushing persistence is not likely to be driven by variation in perceived difficulty or interest, as might occur if we studied daily puzzle completion. Furthermore, toothbrushing is also an activity done by children all over the world, making this paradigm potentially useful in many cultures.

What might influence whether a child brushes longer on a given day? When children decide whether or not to persist, they consider information about expected utilities (cost and rewards), which is often communicated via adults' behavior (Bandura 1977; Leonard et al., 2017; Leonard et al., 2020; Leonard et al., 2021; Lucca \& Sommerville, 2018; Lucca et al., 2019; Lucca et al., 2020). For example, infants and preschoolers pay attention to adults' actions and outcomes and rationally try harder after 


\section{FLUCTUATIONS IN PERSISTENCE}

watching adults' efforts lead to success rather than failure (Leonard et al., 2020; Lucca et al., 2019).

Children also listen to adults' explicit messages about effort: 18-month-olds put in more effort on a gearstacking task if their parents praise their effort, rather than their abilities (Lucca et al., 2019). However, to date no study has looked at how adult behavior varies from day to day, and in turn influences day-to-day fluctuations in children's persistence. Furthermore, most of the work on children's rational learning ignores how physiological states influence behavior, presumably because it is difficult to study children when they are not in a good mood or able to concentrate. Here, we used a novel repeated measures paradigm to investigate four major factors that we predicted would fluctuate from day to day, could be reported with high ecological validity, and based on prior literature, could impact how long children would brush their teeth: parent talk, parent stress, child mood, and child sleep.

A great deal of work has looked at the relationship between adult talk and children's persistence across children. Longitudinal studies have shown a correlation between positive, autonomy-supporting parenting and children's persistence (Deater-Deckard et al., 2006; Frodi et al., 1985; Kelley et al., 2000; Prendergast \& MacPhee, 2018). More specifically, longitudinal and cross-sectional studies find that parent praise for effort, rather than ability is correlated with children's persistence (Gunderson et al., 2013; Lucca et al., 2019). Experimental work has shown a causal impact of specific adult talk. For example, when adults verbally reinforce children's on-task behavior, children try harder (Krantz \& Scratch, 1979; Van Hecke \& Tracy, 1987). Further, when adults praise children's effort over their ability in laboratory tasks (Cimpian et al., 2007; Mueller \& Dweck, 1998), children persist longer. When adults directly instruct children on what to do, it can help children learn explicit information (e.g., learning vocabulary; Dickinson et al., 2019; Klahr \& Nigam, 2004), but can hurt their learning in exploratory learning contexts (e.g., finding a non-obvious function of a toy; Yu et al., 2018; Willard et al., 2019). There is some limited evidence that parent talk fluctuates from day to day, with downstream 


\section{FLUCTUATIONS IN PERSISTENCE}

consequences on child behavior. For example, on days when parents are stressed, they report being less encouraging of their 8-12-year-old's engagement in physical activity (Dunton et al., 2019). However, no study has directly measured fluctuations in parent behavior and their preschooler's behavior over time. Thus, it is unknown whether or how fluctuations in parent behavior shape fluctuations in children's persistence. On the one hand, impacts of parenting may be cumulative, with day-to-day variability having little influence on children's behavior. On the other hand, children may dynamically adjust their behavior, and persist longer, in response to parent behaviors in a given moment.

Children's moods also impact their behavior. Experimentally inducing a pleasant or excited mood in preschoolers leads to greater task persistence (Masters \& Santrock, 1976; Ridgeway \& Waters, 1987). Children's mood may affect persistence both through internal and social mechanisms: positive mood induction causes preschoolers to set more ambitious goals (Hom \& Arbuckle, 1988) and to be more compliant with their parents' requests to complete an effortful task (Lay et al., 1989). Parents can help regulate their children's emotions through modeling emotion regulation themselves and displaying positive affect (Morris et al., 2017). However, it is unclear whether day-to-day fluctuations in child mood relate to daily fluctuations in persistence, or how variations in parent affect and behaviors relate to variations in child mood.

Children's broader physiological states may also impact their persistence on a given day (Bandura, 1977). Work in adults suggests that sleep directly impacts persistence. After one night of sleep loss, adults rate tasks as more effortful (Drummond et al., 2005; Hockey et al., 1998) and prefer lower effort over higher effort tasks, even at the cost of rewards (Engle-Friedman et al., 2003; Libedinsky et al., 2013). Sleep deprivation alters the neural circuits involved with reward valuation, emotional control, and cognitive control, all of which play key roles in effort-based decision making and persistence (Chee \& Chuah, 2007; Gujar et al., 2011; Massar et al., 2019; Yoo et al., 2007). Although the link between sleep 


\section{FLUCTUATIONS IN PERSISTENCE}

and persistence has not yet been studied in children, sleep does impact related behaviors. Toddlers who skip their nap are less able to self-regulate during a challenging task (Miller et al., 2014). Preschoolers with more variable sleep duration are rated by their teachers as adjusting more poorly to preschool (Bates et al., 2002). In school-aged children and adolescents, sleep is related to mood (Könen et al., 2016), working memory (Könen et al., 2015), and performance on standardized tests the next day (Cusick et al., 2018). Young children might be especially vulnerable to the negative consequences of sleep on behavior, as their brains are undergoing rapid large-scale development (Cao et al., 2020; Dewald et al., 2010).

Taken together, prior work points to variation in parents' behavior and stress, as well as children's mood and sleep, as potential influences on fluctuations in children's persistence. To understand how fluctuations in these factors relate to fluctuations in persistence, it is important to measure all variables with high temporal sampling. Technological advances, including the widespread availability of mobile phones, have made daily measurement more feasible. Ecological momentary assessment (EMA) designs collect intensive repeated measures data in everyday settings, as participants go about their daily lives (Shiffman et al., 2008). EMA has been used in preschoolers to explore fluctuations in self-regulation via parent report (Ludwig et al., 2016; Ludwig \& Rauch, 2018) and in toddlers to show how children's physical and social context influence their diet and exercise (Campbell et al., 2018; Hager et al., 2017), but none have directly measured young children's motivational or cognitive processes.

In the current study, parents submitted videos of nightly toothbrushing over 16 days, capturing both children's persistence and parent talk. We focused on evening brushing, rather than morning brushing, because we did not want to interrupt or delay morning routines. Parents also completed daily surveys about their stress, and about child mood and sleep. We examined how fluctuations in parent talk and stress, and child mood and sleep, separately impacted fluctuations in brushing time. We ran separate models testing how each individual factor related to brushing because this approach is directly applicable 


\section{FLUCTUATIONS IN PERSISTENCE}

to targeted interventions focused on specific factors. We predicted that children would brush more when their parents used more praise, and that parents would use less positive talk when they were stressed. We predicted children would brush longer if they were in a better mood, and after they had slept and napped well.

We also explored whether children differed in their sensitivity to psychosocial and physiological influences (Boyce \& Ellis, 2005; Ellis \& Boyce, 2008), and whether their broader social context (socioeconomic status and parent stress over the last month), influenced their sensitivity. This approach allowed us to explore individual differences in children's sensitivity to parenting, mood, and sleep, a critical step towards the creation of personalized interventions. Part of the data for this study was collected prior to the onset of the COVID-19 pandemic, allowing us to ask questions pertaining to how parent behavior, and its relation to child behavior, differed before and after a stressful global event. Finally, we tested whether parents had insight into which factors were most important for their own child's fluctuations in persistence.

\section{Materials and Methods}

This study was exploratory. The Institutional Review Board at [removed for blinding] approved this study. Parents provided informed, electronic consent for their child's participation.

\section{Participants}

Families were recruited through partnerships with local preschools and through social media.

Overall, 90 families enrolled in the study with the goal of 85 usable participants which would allow us to detect an $r$ of .3 with power of .8 in across-participant correlations. One family was excluded for prenatal 


\section{FLUCTUATIONS IN PERSISTENCE}

drug exposure, three families were excluded for sending in unusable or no video data; four families dropped out of the study; and one child was excluded for outlying brushing times $(M=135.94 \mathrm{sec} / \mathrm{night}$, $>3 S D$ from sample mean; though results remain similar when this child is included; see SM Table 1). The final sample consisted of eighty-one three-year-olds ( $M_{\mathrm{age}}=40.84$ months, range $36-47$ months). The racial and ethnic makeup of the sample was as follows: $80 \%$ white, $14 \%$ Multiracial, $10 \%$ Hispanic/Latinx, 2\% Asian, 1\% Black, and 1\% preferred not to answer. Parents were asked to report their child's gender and were provided four options: female, male, other, and prefer not to answer. Forty-eight percent of parents reported that their child's gender was female, and the rest reported that their child's gender was male. The average parental education ranged from 12 to 20 years $(M=16.98, S D=1.75)$. The annual family income ranged from $\$ 14 \mathrm{~K}$ to $\$ 200 \mathrm{~K}(M=\$ 125 \mathrm{~K}, S D=\$ 50 \mathrm{~K})$. Data were collected in two waves: January - June 2019 ( $n=24)$, and March - May 2020 (during the COVID-19 pandemic, $n=57$ ). The two waves matched on age $(t(79)=0.09, p=.93)$, gender $\left(X^{2}(1, n=81)=0.90, p=.34\right)$, and parent education $(t(79)=0.70, p=.49)$. The annual family income was slightly higher in the second wave $(t(75)$ $=2.02, p=.05$; wave one $M=107 \mathrm{~K}$, wave two $M=133 \mathrm{~K})$. To account for possible differences between waves, the study start date was included as a covariate of no interest in multilevel models.

\section{Procedure}

Interested parents filled out a screening questionnaire and were contacted if they had a three-yearold and their child passed the following inclusion criteria: no neurological or psychiatric diagnosis, not born prematurely, speaks English, and tries brushing their own teeth at night. Parents also were required to speak and read English fluently and to have access to a video recording device. Eligible participants were contacted via email with instructions on how to sign up and consent to the study online via REDCap. The online consent was followed by baseline questionnaires ( $\$ 10$ compensation; detailed below). After 


\section{FLUCTUATIONS IN PERSISTENCE}

the surveys, participants were sent instructions on how to participate in the 16-day daily text message portion of the study (see SM Figure 1). We collected data over 16 days to ensure that we had at least 5-8 usable days per child (see analysis plan) without over-burdening families. Participants were sent text message links to surveys in the morning at 8 am (with a reminder 2 hours later if they did not respond) and in the evening at 8:30 pm (with a reminder 1.5 hours later if they did not respond). Participants were compensated $\$ 2 /$ day for completed surveys and an $\$ 8$ bonus for completing all 16 days. The number of daily evening survey days completed by participants ranged from 7 to 16 , with 73\% completing all 16 days $(M=15.33, S D=1.63 ; n=2$ for 7 days; $n=1$ for 11 days; $n=3$ for 13 days; $n=6$ for 14 days; $n=$ 10 for 15 days; $n=59$ for 16 days), and the number of completed morning survey days ranged from 1115 , with $85 \%$ completing all 15 days $(M=14.74, S D=0.72 ; n=1$ for 11 days; $n=1$ for 12 days; $n=4$ for 13 days; $n=6$ for 14 days; $n=69$ for 15 days).

Parents reported their total annual income and education level, as well as the education level of their partner if applicable ( $99 \%$ of parents reported the education level of their partner; education level was averaged if available for both parents; one variable was used if the other was not available). Parent average education and income were normalized and averaged to create a composite measure of socioeconomic status (SES; Bradley \& Corwyn, 2002). Parents filled out the 10-item Perceived Stress Scale (PSS; Cohen \& Williamson, 1988) which indexes parents' feelings of stress in the last month. The 10 items were summed to create the total PSS score.

\section{Daily Measures}

Persistence. Parents sent in a video of their child brushing their teeth every night as part of the evening survey (see Figure 1 and SM Table 2 for details on daily measure administration). Parents were instructed to start recording the video before the toothbrush was in their child's mouth and to stop recording when they took the toothbrush back from the child (see SM Figure 1 for exact instructions). 


\section{FLUCTUATIONS IN PERSISTENCE}

Parents were instructed to let their child brush by themselves for as long as they could before the parent stepped in to finish the job ${ }^{1}$. Persistence was operationalized as the amount of time the child spent brushing their teeth. Using Vcode, two coders (blind to hypotheses) coded all videos for the amount of time that the child spent brushing their teeth (see SM for exact coding scheme). A third coder arbitrated discrepancies over 10 seconds for time brushing between the two coders. Coder scores were highly correlated $(r=0.99, p<.001)$. Time brushing from the two coders was averaged for analyses. If children did not brush their teeth for a night, resulting in no video, parents were instructed to let us know. Children were given a " 0 " if they did not brush at all even after the parent tried to initiate the activity (e.g., "My son refused to brush his own teeth tonight", $n=6$ nights) and were marked as missing data if the parent wasn't able to record (e.g., child was at a sleepover).

Parent talk. All video data were transcribed. One coder coded parent speech from video and the second coder coded parent speech from transcription, and used the video if the context or tone of the transcribed speech was unclear. Agreement between coders was 99\%: of 9391 utterances, the coders disagreed on 30. A third coder arbitrated these disagreements. We coded praise into three different categories based on Gunderson et al. (2013): "process praise” (e.g., "good job”), “person praise” (e.g., "good girl”), and “other praise” (e.g., "very good", “nice”). The majority of praise was classified as "other praise” (462 instances) and "process praise" (349 instances). There were few instances of "person praise" (e.g., "good girl"; 32 instances). However, we did not have the power to analyze the effect of specific types of praise on brushing, so focused our analyses on total praise (the total of all three types of praise). We coded distraction (e.g., singing, reading a book, invoking pretend play) based on prior work showing that selfdistancing promotes children's persistence (White et al., 2017), however distraction was used so infrequently (442 occurrences in 30/82 parents) that we did not have the power to analyze it within or

\footnotetext{
$177 \%$ of participating families said that having their child brush first before brushing for them was in line with their normal brushing routine.
} 


\section{FLUCTUATIONS IN PERSISTENCE}

across children. We coded utterances such as "Brush the backs!" and "keep brushing" as instruction (note that the majority of these utterances were general phrases to keep the child on-task like "keep going" and "brush"; see [osf link] for full transcript). We coded any off-topic or uncategorizable comments (e.g., "How is it going?") as other speech, however we did not have strong hypotheses as to how this heterogeneous speech category would relate to brushing, so we did not analyze it.

Out of 9,145 total utterances from parents, $9 \%$ were praise, $5 \%$ were distraction, $50 \%$ were instruction, and 36\% were other. The full coding scheme is shown in SM Table 3. We constructed a measure of total talk for each subject on each night as the count of total parent utterances per night. To explore the relationship between specific types of parent talk and children's persistence, we created measures of percent praise and percent instruction as the amount of each category of talk divided by total talk per person per night. Parent talk measures were positively and significantly correlated (see SM Table 4).

One family was excluded from parent talk analyses due to poor audio quality in videos. Nights when someone besides the parent was supervising the brushing were excluded ( $n=4$ nights). Children whose parents never used praise or instruction were excluded from multilevel models with those variables, as they could not provide information on how fluctuations in that type of parent talk were associated with fluctuations in brushing behavior ( $n=17$ for praise; $n=1$ for instruction). Children whose parents never used praise did not differ from children whose parents did use praise on SES, gender, parent perceived stress, or parent average stress (all $p \mathrm{~s}>.6$ ).

Parent stress. Parents reported on their stress in the evening survey. They were asked "What is your stress level right now?" They could answer on a 0 (not stressed at all) to 10 (extremely stressed) scale (increments of 1). We measured parent stress with one item to lower parent demands and reduce dropout. We also asked about parent mood, but fluctuations in parent mood were too closely related to 


\section{FLUCTUATIONS IN PERSISTENCE}

fluctuations in parent stress to have separable effects on parent or child behavior $(b=-0.50, p<.0001$; see SM Fig. 2). Hence, we focused our analyses on parent stress based on previous work linking lower parent stress to positive parenting behaviors (Dunton et al., 2019).

Child mood. Parents reported on their child's mood in the evening survey. They were asked "What is your child's mood right now?" and could answer on a 0 (extremely bad) to 10 (extremely good) scale. We measured child mood with one item to minimize demands on parents and reduce dropout.

Sleep duration. We chose to use parent report of child sleep since this measure is accurate, and more inexpensive and feasible for three-year-olds (who often take off wearable electronic trackers) compared to continuous sleep tracking methods like actigraphy (Iwasaki et al., 2010). Parents reported on the time their child went to bed in the evening survey and the time their child woke up in the morning survey, as well as how many times and the total duration that their child was up during the night. Parents also reported whether their child took a nap that day (on the same day as toothbrushing) and the length of the nap. We calculated children's sleep based on their bedtime and wake up time, subtracting any time they were awake at night, and adding in the nap of the current day.

To reduce the possibility that parents would infer our hypotheses, we also asked questions about how much children ate for dinner.

\section{Post-study parent predictions of child behavioral fluctuations}

At the end of the 16-day study, parents responded to the following question by text message: "Which of the following variables (pick as many as apply) do you think related to your child's day-to-day variance in how long they brushed their teeth each night? How much I encouraged them, how much sleep they got the night before, my mood, their mood, my stress, the time of day that they brushed, how much 


\section{FLUCTUATIONS IN PERSISTENCE}

they ate for dinner, or other." Parent prediction data were available for 64 participants because it was first collected midway through the first wave of the study.

\section{Analysis Plan}

Fluctuations in brushing time, parent talk, parent stress, child mood, and child sleep. First, we computed an intraclass correlation (ICC) to identify the proportion of between-person and withinperson variance in daily brushing time. We analyzed the intensive repeated measures data (7-16 days nested in 81 participants) using multilevel models that were parameterized to separate within-person and between-person associations by splitting predictors into time-invariant (between-person) and time-varying (within-person) components (Bolger \& Laurenceau, 2013). There were no significant relationships between the number of evening surveys completed and the key variables: average child sleep $(r(79)=$ $0.10, p=0.37), \operatorname{mood}(r(79)=0.15, p=.17)$, parent stress $(r(79)=-0.10, p=.36)$, percent praise $(r(78)=$ $-0.07, p=.54)$, percent instruction $(r(78)=0.19, p=.09)$, or brushing $(r(79)=-0.10, p=.38)$.

Models were fit using the nlme package in R (Pinheiro et al., 2018) using maximum likelihood estimation. Statistical significance was evaluated at $p=.05$. Children were included in multilevel models if they had at least 5 data points for the two variables of interest, following guidelines from Bolger and Laurenceau (2013). Time-invariant person-level variables for usual percent praise, percent instruction, parent stress, child mood, child sleep, and brushing were calculated as the arithmetic mean across each individual's repeated measures. Time-varying, day-level variables were calculated for percent praise, percent instruction, parent stress, child mood, child sleep, and brushing as deviations from those personspecific means. In these models we controlled for day of study (0-15) and study start date (day 0 - day 483 , to control for any differences associated with the timing of participation relative to the COVID-19 pandemic). 


\section{FLUCTUATIONS IN PERSISTENCE}

We constructed a multilevel model (Level 1) of percent parent praise and brushing as:

TimeBrushing $_{i t}=\beta_{0 i}+\beta_{1 i}$ Praise $_{i t}+\beta_{2 i}$ DayOfStudy $_{i t}+e_{i t}$

where TimeBrushing $_{i t}$ is the time spent brushing for child $i$ on day $t ; \beta_{0 i}$ indicates the expected time brushing on a typical day with an average percent of praise; $\beta_{1 i}$ indicates differences in time brushing associated with changes in day's praise; $\beta_{2 i}$ indicates differences in time brushing as the study progressed to control for time as a third variable (Bolger \& Laurenceau, 2013); $e_{i t}$ are day-specific residuals that were allowed to be autocorrelated (AR1).

Person-specific intercepts and associations (from the Level 1 model) were specified (at Level 2)

as:

$\beta_{0 i}=y_{00}+y_{01}$ UsualPraise $+y_{02}$ StudyStartDate $+u_{0 i}$, and

$\beta_{1 i}=y_{10}+u_{1 i}$

where the $y$ s are sample-level parameters and the $u$ s are residual between-person differences that may be correlated, but are uncorrelated with $e_{i t}$. The parameter $y_{01}$ indicates how usual praise was associated with the usual time spent brushing. The parameter $y_{02}$ indicates how study start date (within each wave, there were multiple study start dates) was associated with the usual time spent brushing. Effect sizes were computed for multilevel models using 'Ime.dscore' from the EMAtools package in R (Kleiman, 2017).

We constructed four more models by replacing parent percent praise with parent percent instruction, parent stress, child mood, and sleep to see how these factors also influenced day-to-day fluctuations in children's time brushing, as well as their usual time spent brushing. To examine how predictor variables related to each other, we ran separate models predicting each variable (percent praise, percent instruction, parent stress, child mood, child sleep) from the other variables. Results were false discovery rate (FDR; Yekutieli \& Benjamini, 1999) corrected at $p<.05$ for multiple comparisons for the 


\section{FLUCTUATIONS IN PERSISTENCE}

$p$-values predicting within-child relationships across the five models (i.e., we FDR-adjusted the five $p$ values for multiple comparisons).

Estimates from Level 2 in the multilevel model were used to explore how average brushing relates to average parent percent praise, parent percent instruction, parent stress, child mood, and sleep controlling for within-subject effects, start date, and day of study. Results were FDR-corrected for multiple comparisons at $p<.05$ for the five $p$-values predicting across-child relationships across predictor models.

\section{Between-subject relationships with demographics and daily measures. We ran individual} correlations relating child age, gender, SES, and parent perceived stress to average brushing time, percent praise, percent instruction, parent stress, child mood, and sleep, as well as variability in each of these measures. We calculated variability as the coefficient of variation (standard deviation across days divided by mean across days; a unit-free variable) (e.g., Levitt et al., 2004; Lydon-Staley et al., 2020). We chose this approach so as not to rely solely on standard deviation, because standard deviation is often related to the mean (Baird et al., 2006; van Geert \& van Dijk, 2002). Results were FDR-corrected at $p<.05$ for multiple comparisons separately for models relating averages and variability.

Individual differences in sensitivity. Individual differences in sensitivity to predictor variables were explored in children for whom data were available for 8 or more nights $(n=61$ for parent percent praise, $n=77$ for parent percent instruction and sleep, $n=78$ for parent stress and child mood). Participants with fewer than 8 data points to contribute to a given model were excluded from these analyses because they lacked sufficient data to give a reliable individual estimate (Jenkins \& Guintana- 


\section{FLUCTUATIONS IN PERSISTENCE}

Ascencio, 2020). Children whose parents exclusively used one type of talk were also excluded from models looking at percent of praise or instruction due to lack of variance ( $n=1$ for percent instruction).

We estimated each individual's sensitivity to each of the five predictor variables (percent praise, percent instruction, parent stress, child mood, and child sleep) by extracting standardized $\beta$ 's from personspecific linear models predicting brushing time with each of the predictor variables separately, controlling for the day of the study. We examined whether sensitivity to each factor was related to sensitivity to other factors and demographic variables (results are FDR-corrected at $p<.05$ for multiple comparisons).

Parent predictions of child behavioral fluctuations. We first calculated the percent of parents who endorsed each of the key predictor variables (encouragement, parent stress, child mood, and sleep) as influential on their child's brushing. We asked parents about encouragement generally rather than specific types of encouragement (e.g., praise) because we thought parents would find this general prompt more interpretable. To test whether parents' guesses were accurate, we compared the absolute value of the standardized $\beta$ of the guessed predictor variable with brushing between children whose parents said the guessed predictor mattered versus those whose parents said the guessed predictor did not matter. We allowed for effects to be both positive and negative because the direction was not stated in the question, i.e., parents could believe that they need to encourage their children more when their children are brushing less well. Analyses were restricted to children who had enough data for sensitivity analyses (see above), and whose parents responded to the question about predicted sensitivity ( $n=48$ for encouragement analyses with praise, $n=62$ for parent stress, child mood, and child sleep).

Impact of COVID-19. To test whether the onset of the COVID-19 pandemic systematically impacted our data, we compared the average and coefficient of variation of brushing time, child sleep, 


\section{FLUCTUATIONS IN PERSISTENCE}

child mood, parent mood, and parent talk variables between the first and second collection data collection waves (data collected in wave two was collected at the beginning of the March 2020 lockdown in the Philadelphia region, where the majority of our data was collected). We also tested for interactions in the multilevel models to determine whether the relationship between predictor variables and day-to-day brushing differed by study enrollment date (which linearly controls for the impact of COVID-19, which we predicted might differ across time). Finally, we tested whether parent self-report of stress at the onset of the study (on the PSS) differed before and after the onset of COVID-19.

\section{Results}

\section{Within-child variability in brushing}

Brushing time varied substantially within and across children (Intraindividual mean $=28.39 \mathrm{sec}$, range $=4.55-74.07 \mathrm{sec}, S D=13.56 \mathrm{sec}$; intraindividual coefficient of variation mean $=0.51$, range $=$ $0.19-1.12, S D=0.21$; see SM Table 5 for variability in predictor variables). Fifty-nine percent of toothbrushing time variance was attributable to within-person variation and $41 \%$ was attributable to between-person variation. Brushing time significantly decreased across days of the study (see Table 1), potentially due to the novelty of being filmed while brushing the first few nights. Multilevel model results indicate that children brushed longer on nights when parents used a higher percent of praise $(b=17.83$, FDR-corrected $p=.008$; Figure 2a). On nights when parents used a higher percent of instruction, children brushed less $(b=-6.61$, FDR-corrected $p=.008$; Figure $2 \mathrm{~b})$.

Children brushed longer when they were in a better mood, but this result did not survive FDR correction $(b=0.64, p=.03$, FDR-corrected $p=.11$; Figure $2 \mathrm{c})$. There was a non-significant positive relationship between sleep and brushing time: children brushed slightly, but not significantly, longer when 


\section{FLUCTUATIONS IN PERSISTENCE}

they slept more the night (and day, if they napped) before they brushed $(b=0.85, p=.08$, Figure $2 \mathrm{~d}$ ). Within-child variation in brushing time was not significantly predicted by parent stress $(b=-0.40, p=.12$, Figure 2e).

\section{Within-child variability in relationships among predictor variables}

Multilevel models revealed that fluctuations in parent stress were related to fluctuations in child mood: parents were less stressed when children were in a better mood $(b=-0.32, p<.001$, FDR-corrected $p<.001$; see SM Table 6$)$, and vice versa $(b=-0.33, p<.001$, FDR-corrected $p<.001)$. Variability in child sleep was related to variability in child mood: when children slept more, they were in a better mood $(b=0.24, p<.001$, FDR-corrected $p=.002)$. Variability in child sleep was also related to variability in parent stress: when children slept more, their parents were less stressed $(b=-0.15, p=.02$, FDR-corrected $p=.21)$

Contrary to our prediction, fluctuations in parent stress were not related to fluctuations in the percentages of parent praise or instruction (SM Table 6). Furthermore, fluctuations in child sleep and mood were not related to fluctuations in the percentages of parent praise or instruction. As expected, because we were looking at percentages of total talk, parent talk types traded off against each other: on nights when instruction made up a greater percent of what parents said, they used a lower percent of praise $(b=-0.18, p<.001$, FDR-corrected $p<.001)$, and on nights when praise made up a greater percent of what parents said, they used a lower percent of instruction $(b=-0.55, p<.001$, FDR-corrected $p$ $<.001)$.

\section{Between-child relationships among brushing, predictor variables, and demographics}




\section{FLUCTUATIONS IN PERSISTENCE}

Across children, average percent parent instruction was negatively associated with average brushing time, but this result did not survive FDR correction (Table 1, MLM: $b=-16.13, p=.04$, FDRcorrected $p=.36)$. Average child mood was positively, but not significantly, associated with average brushing time (Table 1, MLM: $b=2.98, p=.06$, FDR-corrected $p=.36$ ). Average brushing time did not relate to child age, gender, parent average perceived stress, or SES (see SM Table 7).

Variability in brushing time (coefficient of variation) was negatively related to SES: children from lower SES backgrounds had more variable brushing times $(r(79)=-0.43$, FDR-corrected $p=.01 ; \mathrm{SM}$ Table 8). Parents who indicated higher perceived stress at the beginning of the study had higher stress $(r(79)=0.51$, FDR corrected $p<.001)$ and lower variability in parent stress throughout the study $(r(79)=$ -0.38$, FDR corrected $p=.04)$. No other relationships among demographics and EMA measure averages and variability were significant after FDR correction (SM Tables 7 and 8).

\section{Individual differences in brushing sensitivity to predictor variables}

Sensitivity to mood was negatively related to sensitivity to parent stress: children who brushed more when they were in a good mood brushed less when their parents were stressed (Table $2, r(76)=$ $0.45, p<.001$, FDR-corrected $p=.002)$. Children who brushed more when their parent used a greater percent of praise, brushed less when their parent used a greater percent of instruction $($ Table $2, r(58)=$ $0.53, p<.001$, FDR-corrected $p=.002$ ). All other relationships between sensitivity to fluctuations in predictor variables and demographics did not survive FDR correction for multiple comparisons (see Table 2; SM Table 9 for outlier analyses - results do not change).

\section{Parent predictions of child brushing sensitivity}




\section{FLUCTUATIONS IN PERSISTENCE}

In order from most commonly endorsed to least commonly endorsed, parents thought the following factors impacted their children's brushing: child mood (92\%), parent encouragement (65\%), parent stress (50\%), child sleep (18\%). However, for the parents who thought that their child's mood mattered for brushing, their child's sensitivity to mood (absolute value of $\beta$ ) was not higher than for children whose parents did not think their child mood mattered $(t(60)=-0.63, p=.55)$. The same was true for parent encouragement (percent praise: $t(48)=-1.59, p=.12$ ), and parent stress $(t(60)=1.10, p=.28)$. Parents who thought that child sleep did not matter for brushing actually had children on average for whom sleep did matter for brushing $(t(60)=2.74, p=.01)$.

\section{Impact of COVID-19}

Some data were collected before the pandemic ( $n=24$, January - June 2019), and some were collected during the early stages of the COVID-19 pandemic ( $n=57$, March - May 2020). Parent perceived stress (reported via a questionnaire at the beginning of the study) was higher during the pandemic $(t(79)=2.55, p=.01)$, but parent average daily stress did not differ between pre-COVID and COVID epochs $(t(79)=1.17, p=.25)$. Praise and instruction percentages did not differ between preCOVID and COVID epochs (percent praise: $t(78)=-1.01, p=.32$; percent instruction: $t(78)=0.34, p$ $=.73$ ) and the relationship between parent talk measures and brushing did not change by epoch (see SM Table 10). Children's average sleep, mood, and brushing time did not differ by study start date (sleep: $t(79)=1.51, p=.14$, mood: $t(79)=-0.06, p=.95$, brushing time: $t(79)=-0.87, p=.39)$, nor did associations among sleep, mood, stress, and toothbrushing (see SM Table 10).

\section{Robustness to analytical decisions}




\section{FLUCTUATIONS IN PERSISTENCE}

Due to the exploratory nature of this study, we checked whether our main results were robust to analytical decisions. We ran one model to test whether percent praise, percent instruction, and child mood uniquely predicted fluctuations in persistence above and beyond other factors. In this model, which included 62 children with data on all variables, within-child variation in percent praise positively predicted brushing (percent praise: $b=13.92, p=.009$; see SM Table 11). Mood also positively predicted brushing $(b=0.93, p=.02)$. The relationship between percent instruction and within-child brushing was close, but not significant $(b=-5.05, p=.056)$.

We also ran multilevel models including one participant with outlying brushing time $(M=135.94$ sec/night, $>3 S D$ from sample mean) and found that percent praise still positively related to brushing and percent instruction still negatively related to brushing (percent praise: $b=12.60, p=.02$, FDR-corrected $p$ $=.09$; percent direct instruction: $b=-6.84, p=.004$, FDR-corrected $p=.05$; see SM Table 1).

We focused on parent daily stress instead of mood because they were so highly correlated, but when we averaged the two measures of parent affect together to predict within-child variations in brushing, results were still null $(b=-0.01, p=.98$; see SM Table 12). Finally, all coded and deidentified data are publicly available on the OSF (link hidden for blind review) and identified video data is available upon request for other researchers to explore different coding techniques and run follow-up analyses.

\section{Discussion}

Young children's persistence fluctuated substantially from day to day. Within children, variation in persistence was related to variation in parent talk: Children's time spent brushing their teeth was positively correlated with parent praise and negatively correlated with parent instruction. These results were robust to various analytical decisions. Fluctuations in child mood were also associated with fluctuations in brushing, but this effect was weaker and more variable across children. Fluctuations in 


\section{FLUCTUATIONS IN PERSISTENCE}

parent stress and child sleep were not related to children's persistence, but were related to child mood.

Some children were more sensitive to fluctuations in predictor variables than others: children who were sensitive to variability in parent stress were also sensitive to variability in their own mood, and children who were sensitive to variability in parent praise were also sensitive to variability in parent instruction. Parents were not able to accurately predict which variables shaped brushing in their own children, but their guesses were consistent with the overall importance of parent encouragement and child mood.

Our work is the first to show that fluctuations in parent praise relate to fluctuations in child persistence within a family, providing better evidence than between-family studies that parent praise relates to children's behavior, and does not just reflect broader positive aspects of a child's environment. Why might praise impact children's behavior in the moment? Drawing upon a utility framework of effortbased decision making (Inzlicht et al., 2018; Kurzban et al., 2013), parent praise might be a reward for effortful action in a given moment. However, the data is still correlational, and it is also possible that better child persistence elicits more positive feedback from parents. Untangling cause and effect is especially difficult given the current paradigm's reliance on two cumulative, co-occurring measures. Intervention studies to induce more praise from parents are necessary to determine whether praise causally impacts persistence in naturalistic contexts the way it does in laboratory experiments (Cimpian et al., 2007; Mueller \& Dweck, 1998; Yu et al., 2018).

Parent instruction, on the other hand, may not be an effective strategy to help children brush, or parents may use instruction more when a child is off-task. Instruction may also reduce the time children spend brushing because they are able to brush more efficiently. However, it is difficult to assess the quality of brushing from video data alone. Furthermore, we chose time spent brushing as the dependent measure because it is what most dentists recommend tracking, rather than efficiency, which is harder to 


\section{FLUCTUATIONS IN PERSISTENCE}

measure. It could also be the case that instruction is more helpful in circumstances that require a high level of skill, like when children are trying to learn piano.

There was a positive relationship between children's mood and brushing time, but this result was weak and variable across children. Past work has found a causal impact of positive mood on persistence in four-year-old children (Masters \& Santrock, 1976; Ridgeway \& Waters, 1987), suggesting that having a positive mood may lead to longer brushing on a given day. Positive mood might increase children's persistence through multiple mechanisms, including increasing children's willingness to comply with parent requests (Lay et al., 1989), decreasing the subjective cost of errors (Pourtois et al., 2017), increasing self-efficacy (Hom \& Arbuckle, 1988), or changing interactions with parents. Here, we observed that fluctuations in mood were also related to fluctuations in parent stress. This relationship is almost certainly bidirectional: children's moods may deteriorate when their parents are stressed, and parents may feel more stressed when their children are in a bad mood. Mood and persistence may also reflect similar underlying physiological processes like fatigue. Experiments that induce positive mood in children, possibly through fun parent-child games prior to brushing, are necessary to test whether positive mood causes more brushing.

Our results show the advantages of measuring experiences within rather than just across children. None of the variables that we measured significantly predicted individual differences in average brushing time. Thus, it is not the case that parents who on average use more praise and less instruction have children who on average brush more. Measuring individual variation in brushing also revealed that more variable brushing time was associated with lower SES, suggesting that repeated measures may be even more important for characterizing behaviors for children in low-SES environments.

There were large individual differences in which factors were most predictive of brushing. For every predictor, some children showed positive effects, and others showed negative effects. Some 


\section{FLUCTUATIONS IN PERSISTENCE}

children were sensitive to affective states, brushing more when they were in a better mood and less when their parents were stressed. We did not find an effect of SES on sensitivity to any of the factors, but the SES range was narrow, with only 4 families reporting incomes less than $\$ 62,500$ per year. Larger and more diverse samples are needed to determine what makes some children sensitive to sleep, some sensitive to parent talk, and others sensitive to affective states. It is also possible that more than two weeks of data are necessary to precisely detect an individual child's sensitivity.

At the end of the study, parents were asked which factors influenced their own child's brushing. The majority of parents chose parent encouragement and mood, consistent with the within-child effects observed in the study. However, parents were not accurate in guessing which factors were most important for their own child. It is possible that parents answered this question based on their impressions of the quality of their child's brushing or their skill level, rather than the fine-grained brushing time that we measured here. These results point to the potential benefit of providing parents with individualized information about the causes of variability in their children's behavior.

Data collected before and during the pandemic suggest that the factors that proximally shape variability in children's persistence are fairly consistent regardless of broader global contexts and schedule disruptions. It is possible parents have been able to provide a buffer for their children against stressors in the world, even if they internalize the stress themselves, at least in the few minutes that we observed in this fairly affluent sample at the very beginning of the pandemic. Whether these results hold as the pandemic has stretched on remains an open question.

A major contribution of this work is the development of a new task to measure fluctuations in persistence. We chose to study fluctuations in persistence in an ecological domain in which parents want children to persist: brushing their teeth. Toothbrushing has no immediate pay-off and is not especially intrinsically motivating, reflecting a feature shared by many tasks that require persistence in both children 


\section{FLUCTUATIONS IN PERSISTENCE}

and adults, like cleaning one's room and getting dressed. However, we do not know how the factors that shape persistence here will generalize to other tasks that require persistence. We intentionally chose a task that was not likely to be sensitive to individual differences in cognitive ability, so traditional models of effort might be less relevant for predicting behavior. Future work should test whether findings reported here translate to children's daily fluctuations on a wider range of tasks that require persistence, including those with both more immediate and delayed rewards. Notably, this daily video framework can be extended to study fluctuations in persistence in other domains that are more cognitively challenging or rewarding, like completing difficult homework or practicing a musical instrument, as suggested in Muenks, Wigfield, and Eccles (2018).

This study has a number of limitations. First, although toothbrushing is an ecologically valid task, its psychometric properties are not yet known and it may involve skills related to persistence, like executive function, conscientiousness, and compliance. Second, our sample is skewed towards higherincome families within a Western, Educated, Industrialized, Rich, and Democratic (WEIRD) cultural context, and thus we cannot address how our findings might differ in other contexts. Third, although we were able to measure persistence and parent talk objectively with video data, we relied on parent report for measures of child sleep, parent stress, and child mood. Parent report of child mood could be biased by their observation of a child's behavior during brushing. Parent report of both their stress and child mood may have artificially inflated the relationship between the two. Questions were brief to limit parent time commitment and reduce drop out, but they were limited in the amount of detail they provided. Many other unmeasured features of children's environments may also impact their persistence (e.g., exercise; Ludwig \& Rauch, 2018). Fourth, we did not collect data on the quality of children's sleep. Although parent report of young children's sleep has been shown to be comparable to more intensive measures like actigraphy (Iwasaki et al., 2010), the use of actigraphy may help with precision for data on factors like nighttime 


\section{FLUCTUATIONS IN PERSISTENCE}

waking (Lam et al., 2011). Furthermore, parents whose children attended childcare may have reported on naps without direct observation on some days. Fifth, we focused on evening brushing, but some relationships between predictor variables and persistence may be stronger during morning brushing (e.g., the relationship with sleep). Thus, future studies should probe time of day effects. Sixth, parents may have modified their own behavior due to being observed, potentially lowering the ecological validity of their parenting practices. Seventh, we do not know if our results will generalize beyond the pandemic, but comparisons with pre-pandemic data suggest that major differences are unlikely. Eighth, we were underpowered to run interactions, which require substantially larger sample size (e.g., Heo \& Leon, 2010), or more complex time lagged analyses, which may require more time points per child . Future research with larger samples, and/or more occasions of sampling, should probe whether predictor variables interact in meaningful ways to impact fluctuations in brushing (e.g., are children more responsive to social input after a good night sleep?). Finally, this study was exploratory in nature and positive results merit replication in an independent sample.

A major strength of this work was that daily video data gave us a window into children's lives by capturing their naturalistic persistence and interactions with their parents. Our methods allowed us to go beyond measuring children's behavior solely via parent report, or with a snapshot measure in the lab that may be sensitive to unmeasured fluctuations in children's attention and motivation. This approach has implications for developmental science broadly. Measuring behavior every day will lead to a better estimate of average behavior, as well as estimates of variability in behavior, particularly in young children who may be difficult to study in laboratory settings. These measures may be, for example, more related to brain structure and function than performance on a snapshot measure in the lab. Intensive repeated measures will also be helpful for testing computational models of cognitive development. Clinically, daily at-home videos of child behavior can go beyond parent report to track variation in symptoms like 


\section{FLUCTUATIONS IN PERSISTENCE}

inattention, hyperactivity, defiance, and oppositional behaviors and to understand the factors that contribute to variability. By capturing naturalistic family dynamics, this method can be helpful for understanding susceptibility and resilience to adversity.

In sum, we found that children's persistence fluctuates from day to day and is shaped by parent behavior. Our results inform both old and new theoretical models of persistence. We add nuance to Bandura's theory (1977) that verbal persuasion impacts persistence by specifically showing that praise, but not instruction, is associated with greater persistence. Our work replicates prior work in the praise literature showing that adult praise motivates children (Brummelman \& Dweck, 2020; Cimpian, et al., 2007; Gunderson et al., 2013, 2018; Lucca et al., 2019; Mueller \& Dweck, 1998). We add to this literature by characterizing naturalistic parent praise over multiple days: parent praise during the daily task of toothbrushing mostly consisted of generic praise and process praise (e.g., "nice!" and "great job!"), with few instances of person praise (e.g., "good girl”). Furthermore, we show that the quantity of parent praise positively relates to individual children's persistence across days, building on empirical and theoretical work suggesting that general praise is helpful on tasks focused on continued commitment towards a goal (Eskreis-Winkler \& Fishbach, 2020). Beyond verbal and social input, we show that children's own physiological states may matter more for some children more than others. We also expand on modern theories of children as utility maximizers (Lucca et al., 2020) by suggesting that the costs and rewards of effortful actions may fluctuate from day to day depending on social feedback and physiological states.

Our work provides a path towards identifying the specific factors that impact individual children's persistence to design targeted interventions, some of which parents may not find obvious. For children who are most sensitive to parent stress, we can recommend interventions to enhance parent emotion regulation (England-Mason \& Gonzalez, 2020). For children who are most sensitive to sleep, interventions that target sleep hygiene might be more effective (Wilson et al., 2014). Group-level 


\section{FLUCTUATIONS IN PERSISTENCE}

interventions that enhance children's motivation and cognition have been frustratingly elusive (Bailey et al., 2020; Diamond \& Ling, 2016), and individualization may be the key to better efficacy. 
FLUCTUATIONS IN PERSISTENCE

\section{References}

Bandura, A. (1977). Self-efficacy: Toward a unifying theory of behavioral change. Psychological Review, 84(2), 191. https://doi.org/10.1037/0033-295X.84.2.191

Bailey, D. H., Duncan, G. J., Cunha, F., Foorman, B. R., \& Yeager, D. S. (2020). Persistence and fadeout in the impacts of child and adolescent interventions. Psychological Science in the Public Interest. https://doi.org/10.1177/1529100620915848

Baird, B. M., Le, K., \& Lucas, R. E. (2006). On the nature of intraindividual personality variability: Reliability, validity, and associations with well-being. Journal of Personality and Social Psychology, 90(3), 512-527. https://doi.org/10.1037/0022-3514.90.3.512

Bates, J. E., Viken, R. J., Alexander, D. B., Beyers, J., \& Stockton, L. (2002). Sleep and adjustment in preschool children: Sleep diary reports by mothers relate to behavior reports by teachers. Child Development, 73(1), 62-75. https://doi.org/10.1111/1467-8624.00392

Bolger, N., \& Laurenceau, J.-P. (2013). Intensive longitudinal methods: An introduction to diary and experience sampling research. Guilford Press.

Boyce, W. T., \& Ellis, B. J. (2005). Biological sensitivity to context: I. An evolutionary-developmental theory of the origins and functions of stress reactivity. Development and Psychopathology, 17(2), 271-301. https://doi.org/10.1017/S0954579405050145

Bradley, R. H., \& Corwyn, R. F. (2002). Socioeconomic status and child development. Annual Review of Psychology, 53(1), 371-399. https://doi.org/10.1146/annurev.psych.53.100901.135233

Brummelman, E., \& Dweck, C. S. (2020). Paradoxical effects of praise: A transactional model. In Psychological Perspectives on Praise. Routledge. 


\section{FLUCTUATIONS IN PERSISTENCE}

Campbell, K. L., Babiarz, A., Wang, Y., Tilton, N. A., Black, M. M., \& Hager, E. R. (2018). Factors in the home environment associated with toddler diet: An ecological momentary assessment study. Public Health Nutrition, 21(10), 1855-1864. https://doi.org/10.1017/S1368980018000186

Cao, J., Herman, Alexander B., West, G. B., Poe, G., \& Savage, V. M. (2020). Unraveling why we sleep: Quantitative analysis reveals abrupt transition from neural reorganization to repair in early development | Science Advances. Science Advances, 6(38). https://advances.sciencemag.org/content/6/38/eaba0398?intcmp=trendmd-adv

Chee, M. W. L., \& Chuah, Y. M. L. (2007). Functional neuroimaging and behavioral correlates of capacity decline in visual short-term memory after sleep deprivation. Proceedings of the National Academy of Sciences, 104(22), 9487-9492. https://doi.org/10.1073/pnas.0610712104

Cimpian, A., Arce, H. M. C., Markman, E. M., \& Dweck, C. S. (2007). Subtle linguistic cues affect children's motivation. https://journals.sagepub.com/doi/full/10.1111/j.1467-9280.2007.01896.x

Cusick, C. N., Isaacson, P. A., Langberg, J. M., \& Becker, S. P. (2018). Last night's sleep in relation to academic achievement and neurocognitive testing performance in adolescents with and without ADHD. Sleep Medicine, 52, 75. https://doi.org/10.1016/j.sleep.2018.07.014

Deater-Deckard, K., Petrill, S. A., Thompson, L. A., \& DeThorne, L. S. (2006). A longitudinal behavioral genetic analysis of task persistence. Developmental Science, 9(5), 498-504.

https://doi.org/10.1111/j.1467-7687.2006.00517.x

Dewald, J. F., Meijer, A. M., Oort, F. J., \& Kerkhof, G. A. (2010). The influence of sleep quality, sleep duration and sleepiness on school performance in children and adolescents: A meta-analytic review. Sleep Medicine Reviews, 11. 


\section{FLUCTUATIONS IN PERSISTENCE}

Diamond, A., \& Ling, D. S. (2016). Conclusions about interventions, programs, and approaches for improving executive functions that appear justified and those that, despite much hype, do not. Developmental Cognitive Neuroscience, 18, 34-48. https://doi.org/10.1016/j.dcn.2015.11.005

Drummond, S. P. A., Meloy, M. J., Yanagi, M. A., Orff, H. J., \& Brown, G. G. (2005). Compensatory recruitment after sleep deprivation and the relationship with performance. Psychiatry Research: Neuroimaging, 140(3), 211-223. https://doi.org/10.1016/j.pscychresns.2005.06.007

Duckworth, A. L., Peterson, C., Matthews, M. D., \& Kelly, D. R. (2007). Grit: Perseverance and passion for long-term goals. Journal of Personality and Social Psychology, 92(6), 1087-1101. https://doi.org/10.1037/0022-3514.92.6.1087

Dunton, G. F., Ke, W., Dzubur, E., O’Connor, S. G., Lopez, N. V., \& Margolin, G. (2019). Withinsubject effects of stress on weight-related parenting practices in mothers: An ecological momentary assessment study. Annals of Behavioral Medicine, 53(5), 415-425. https://doi.org/10.1093/abm/kay053

Ellis, B. J., \& Boyce, W. T. (2008). Biological sensitivity to context. Current Directions in Psychological Science, 17(3), 183-187. JSTOR.

England-Mason, G., \& Gonzalez, A. (2020). Intervening to shape children's emotion regulation: A review of emotion socialization parenting programs for young children. Emotion, 20(1), 98-104. https://doi.org/10.1037/emo0000638

Engle-Friedman, M., Riela, S., Golan, R., Ventuneac, A. M., Davis, C. M., Jefferson, A. D., \& Major, D. (2003). The effect of sleep loss on next day effort. Journal of Sleep Research, 12(2), 113-124. https://doi.org/10.1046/j.1365-2869.2003.00351.x 


\section{FLUCTUATIONS IN PERSISTENCE}

Eskreis-Winkler, L., \& Fishbach, A. (2020). When praise-versus criticism-motivates goal pursuit. In E. Brummelman (Ed.), Psychological Perspectives on Praise (1st ed., pp. 47-54). Routledge. https://doi.org/10.4324/9780429327667-8

Frodi, A., Bridges, L., \& Grolnick, W. (1985). Correlates of Mastery-Related Behavior: A Short-Term Longitudinal Study of Infants in Their Second Year. Child Development, 56(5), 1291-1298. JSTOR. https://doi.org/10.2307/1130244

Gujar, N., Yoo, S.-S., Hu, P., \& Walker, M. P. (2011). Sleep deprivation amplifies reactivity of brain reward networks, biasing the appraisal of positive emotional experiences. Journal of Neuroscience, 31(12), 4466-4474. https://doi.org/10.1523/JNEUROSCI.3220-10.2011

Gunderson, E. A., Gripshover, S. J., Romero, C., Dweck, C. S., Goldin-Meadow, S., \& Levine, S. C. (2013). Parent praise to 1- to 3-year-olds predicts children's motivational frameworks 5 years later. Child Development, 84(5), 1526-1541. https://doi.org/10.1111/cdev.12064

Gunderson, E. A., Sorhagen, N. S., Gripshover, S. J., Dweck, C. S., Goldin-Meadow, S., \& Levine, S. C. (2018). Parent praise to toddlers predicts fourth grade academic achievement via children's incremental mindsets. Developmental Psychology, 54(3), 397-409. https://doi.org/10.1037/dev0000444

Hager, E. R., Tilton, N. A., Wang, Y., Kapur, N. C., Arbaiza, R., Merry, B. C., \& Black, M. M. (2017). The home environment and toddler physical activity: An ecological momentary assessment study. Pediatric Obesity, 12(1), 1-9. https://doi.org/10.1111/ijpo.12098

Heo, M., \& Leon, A. C. (2010). Sample sizes required to detect two-way and three-way interactions involving slope differences in mixed-effects linear models. Journal of Biopharmaceutical Statistics, 20(4), 787-802. https://doi.org/10.1080/10543401003618819 


\section{FLUCTUATIONS IN PERSISTENCE}

Hockey, G. R. J., Wastell, D. G., \& Sauer, J. (1998). Effects of sleep deprivation and user interface on complex performance: A multilevel analysis of compensatory control. Human Factors, 40(2), 233-253. https://doi.org/10.1518/001872098779480479

Hom, H. L., \& Arbuckle, B. (1988). Mood induction effects upon goal setting and performance in young children. Motivation and Emotion, 12(2), 113-122. https://doi.org/10.1007/BF00992168

Inzlicht, M., Shenhav, A., \& Olivola, C. Y. (2018). The Effort Paradox: Effort Is both costly and valued. Trends in Cognitive Sciences, 22(4), 337-349. https://doi.org/10.1016/j.tics.2018.01.007

Iwasaki, M., Iwata, S., Iemura, A., Yamashita, N., Tomino, Y., Anme, T., Yamagata, Z., Iwata, O., \& Matsuishi, T. (2010). Utility of subjective sleep assessment tools for healthy preschool hildren: A comparative study between sleep Logs, questionnaires, and actigraphy. Journal of Epidemiology, 20(2), 143-149. https://doi.org/10.2188/jea.JE20090054

Kelley, S. A., Brownell, C. A., \& Campbell, S. B. (2000). Mastery motivation and self-evaluative affect in toddlers: Longitudinal relations with maternal behavior. Child Development, 71(4), 1061-1071. https://doi.org/10.1111/1467-8624.00209

Könen, T., Dirk, J., Leonhardt, A., \& Schmiedek, F. (2016). The interplay between sleep behavior and affect in elementary school children's daily life. Journal of Experimental Child Psychology, 150, 1-15. https://doi.org/10.1016/j.jecp.2016.04.003

Könen, T., Dirk, J., \& Schmiedek, F. (2015). Cognitive benefits of last night's sleep: Daily variations in children's sleep behavior are related to working memory fluctuations. Journal of Child Psychology and Psychiatry, 56(2), 171-182. https://doi.org/10.1111/jcpp.12296

Kurzban, R., Duckworth, A., Kable, J. W., \& Myers, J. (2013). An opportunity cost model of subjective effort and task performance. Behavioral and Brain Sciences, 36(6), 661-679. https://doi.org/10.1017/S0140525X12003196 


\section{FLUCTUATIONS IN PERSISTENCE}

Lam, J. C., Mahone, E. M., Mason, T. B. A., \& Scharf, S. M. (2011). Defining the roles of actigraphy and parent logs for assessing sleep variables in preschool children. Behavioral Sleep Medicine, 9(3), 184-193. https://doi.org/10.1080/15402002.2011.583906

Lay, K.-L., Waters, E., \& Park, K. A. (1989). Maternal responsiveness and child compliance: The role of mood as a mediator. Child Development, 60(6), 1405-1411. JSTOR.

https://doi.org/10.2307/1130930

Levitt, H., Wood, A., Moul, D. E., Hall, M., Germain, A., Kupfer, D. J., \& Buysse, D. J. (2004). A pilot study of subjective daytime alertness and mood in primary insomnia participants using ecological momentary assessment. Behavioral Sleep Medicine, 2(2), 113-131. https://doi.org/10.1207/s15402010bsm0202_3

Libedinsky, C., Massar, S. A. A., Ling, A., Chee, W., Huettel, S. A., \& Chee, M. W. L. (2013). Sleep deprivation alters effort discounting but not delay discounting of monetary rewards. Sleep, 36(6), 899-904. https://doi.org/10.5665/sleep.2720

Lucca, K., Horton, R., \& Sommerville, J. A. (2019). Keep trying!: Parental language predicts infants' persistence. Cognition, 193, 104025. https://doi.org/10.1016/j.cognition.2019.104025

Ludwig, K., Haindl, A., Laufs, R., \& Rauch, W. A. (2016). Self-regulation in preschool children's everyday life: Exploring day-to-day variability and the within- and between-person structure. Journal of Self-Regulation and Regulation, 2, 99-117. https://doi.org/10.11588/josar.2016.2.34357

Ludwig, K., \& Rauch, W. A. (2018). Associations between physical activity, positive affect, and selfregulation during preschoolers' everyday lives. Mental Health and Physical Activity, 15, 63-70. https://doi.org/10.1016/j.mhpa.2018.07.002 


\section{FLUCTUATIONS IN PERSISTENCE}

Lydon-Staley, D. M., Zurn, P., \& Bassett, D. S. (2020). Within-person variability in curiosity during daily life and associations with well-being. Journal of Personality, 88(4), 625-641. https://doi.org/10.1111/jopy.12515

Massar, S. A. A., Lim, J., \& Huettel, S. A. (2019). Sleep deprivation, effort allocation and performance. In Progress in Brain Research (Vol. 246, pp. 1-26). Elsevier. https://doi.org/10.1016/bs.pbr.2019.03.007

Masters, J. C., \& Santrock, J. W. (1976). Studies in the self-regulation of behavior: Effects of contingent cognitive and affective events. Developmental Psychology, 12(4), 334-348. https://doi.org/10.1037/0012-1649.12.4.334

Miller, A. L., Seifer, Ronald, Crossin, Rebecca, \& Lebourgeois, Monique K. (2014). Toddler's selfregulation strategies in a challenge context are nap-dependent. Journal of Sleep Research, 24(3). https://onlinelibrary.wiley.com/doi/full/10.1111/jsr.12260

Mischel, W., Shoda, Y., \& Rodriguez, M. I. (1989). Delay of gratification in children. Science, 244(4907), 933-938. https://doi.org/10.1126/science.2658056

Morris, A. S., Criss, M. M., Silk, J. S., \& Houltberg, B. J. (2017). The impact of parenting on emotion regulation during childhood and adolescence. Child Development Perspectives, 11(4), 233-238. https://doi.org/10.1111/cdep.12238

Mueller, C. M., \& Dweck, C. S. (1998). Praise for intelligence can undermine children's motivation and performance. Journal of Personality and Social Psychology, 75(1), 20.

Muenks, K., Wigfield, A., \& Eccles, J. S. (2018). I can do this! The development and calibration of children's expectations for success and competence beliefs. Developmental Review, 48, 24-39. https://doi.org/10.1016/j.dr.2018.04.001 


\section{FLUCTUATIONS IN PERSISTENCE}

Oeri, N., \& Roebers, C. M. (2020). Task persistence in kindergarten children: Disentangling age from schooling effects. British Journal of Developmental Psychology, n/a(n/a). https://doi.org/10.1111/bjdp.12358

Pourtois, G., Vanlessen, N., Bakic, J., \& Paul, K. (2017). Modulatory effects of positive mood on cognition: Lessons from attention and error monitoring. Current Directions in Psychological Science, 26(6), 495-501. https://doi.org/10.1177/0963721417709551

Prendergast, S., \& MacPhee, D. (2018). Parental contributors to children's persistence and school readiness. Early Childhood Research Quarterly, 45, 31-44. https://doi.org/10.1016/j.ecresq.2018.05.005

Ridgeway, D., \& Waters, E. (1987). Induced mood and preschoolers' behavior: Isolating the effects of hedonic tone and degree of arousal. Journal of Personality and Social Psychology, 52(3), 620625. https://doi.org/10.1037/0022-3514.52.3.620

Saudino, K. J., Plomin, R., \& DeFries, J. C. (1996). Tester-rated temperament at 14, 20 and 24 months: Environmental change and genetic continuity. British Journal of Developmental Psychology, 14(2), 129-144. https://doi.org/10.1111/j.2044-835X.1996.tb00697.x

Shiffman, S., Stone, A. A., \& Hufford, M. R. (2008). Ecological momentary assessment. Annual Review of Clinical Psychology, 4(1), 1-32. https://doi.org/10.1146/annurev.clinpsy.3.022806.091415

van Geert, P., \& van Dijk, M. (2002). Focus on variability: New tools to study intra-individual variability in developmental data. Infant Behavior and Development, 25(4), 340-374.

https://doi.org/10.1016/S0163-6383(02)00140-6

Van Hecke, M., \& Tracy, R. J. (1987). The influence of adult encouragement on children's persistence. Child Study Journal, 17(4), 251-268. 


\section{FLUCTUATIONS IN PERSISTENCE}

Wilson, K. E., Miller, A. L., Bonuck, K., Lumeng, J. C., \& Chervin, R. D. (2014). Evaluation of a sleep education Program for low-income preschool children and their families. Sleep, 37(6), 1117-1125. https://doi.org/10.5665/sleep.3774

Yoo, S.-S., Gujar, N., Hu, P., Jolesz, F. A., \& Walker, M. P. (2007). The human emotional brain without sleep_A prefrontal amygdala disconnect. Current Biology, 17(20), R877-R878.

https://doi.org/10.1016/j.cub.2007.08.007

Zhou, Q., Hofer, C., Eisenberg, N., Reiser, M., Spinrad, T. L., \& Fabes, R. A. (2007). The developmental trajectories of attention focusing, attentional and behavioral persistence, and externalizing problems during school-age years. Developmental Psychology, 43(2), 369-385.

https://doi.org/10.1037/0012-1649.43.2.369 


\section{FLUCTUATIONS IN PERSISTENCE}

Figure 1. Toothbrushing procedure and data. A. Screenshots of child participants (with parent permission). B. An example participant's time spent brushing data (black, left axis) and mood data (pink, right axis) as a time series. C. The same participant's brushing data and mood data as a correlation.

a.
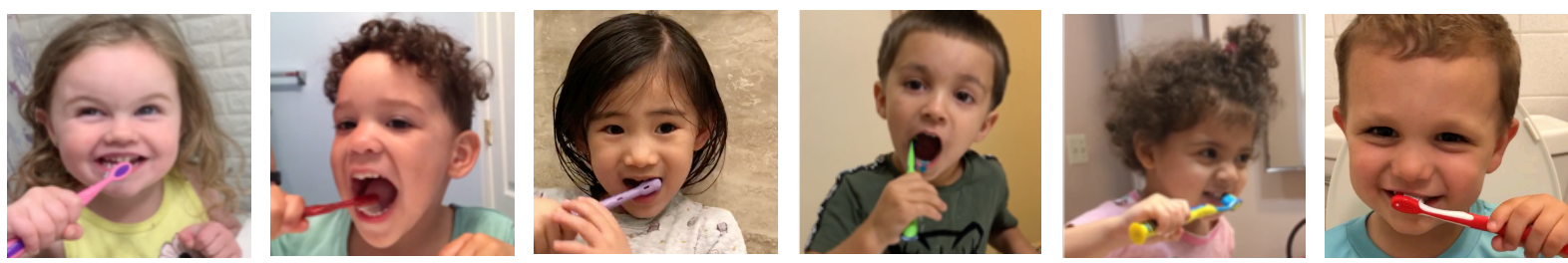

b

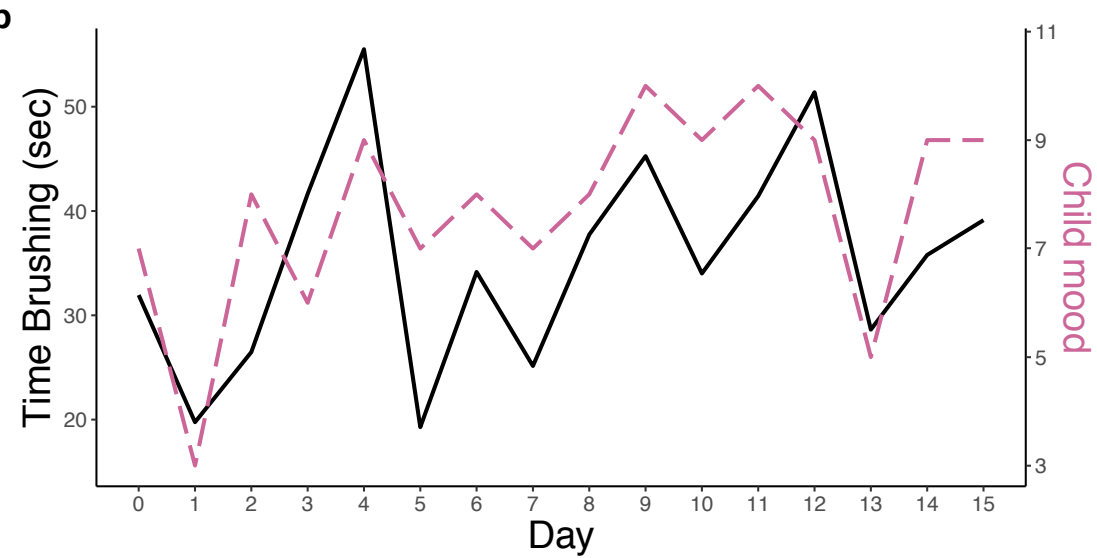

c.

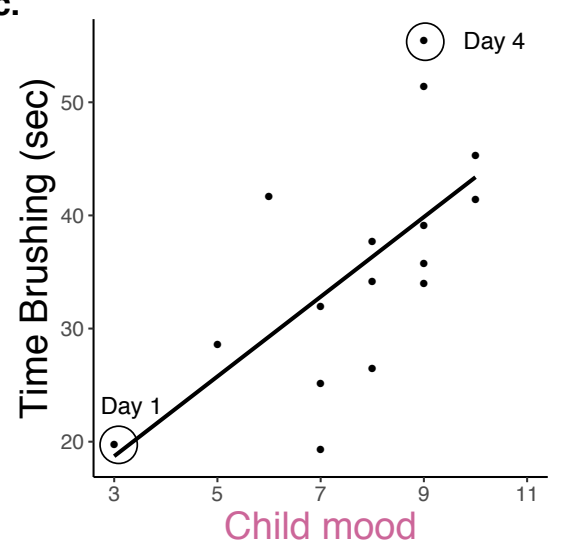




\section{FLUCTUATIONS IN PERSISTENCE}

Table 1. Multilevel models predicting brushing time. Estimates are not standardized. Usual sleep includes naps. * Uncorrected $p<.05, * *$ FDR-corrected at $p<.05$ for within-child factors and betweenchild factors separately.

\begin{tabular}{|c|c|c|c|c|c|c|c|}
\hline & & Estimate $(b)$ & $S E$ & df & $t$ & $p$ & $d$ \\
\hline \multirow[t]{5}{*}{$\%$ Praise } & Intercept & 38.27 & 4.08 & 799 & 9.37 & $<0.001$ & \\
\hline & Day's \% praise** & 17.83 & 5.55 & 799 & 3.21 & 0.001 & 0.23 \\
\hline & Usual \% praise & -12.99 & 24.61 & 60 & -0.53 & 0.60 & \\
\hline & Start date & -0.01 & 0.01 & 60 & -1.15 & 0.25 & \\
\hline & Day of study* & -0.54 & 0.14 & 799 & -3.88 & $<0.001$ & -0.27 \\
\hline \multirow[t]{5}{*}{$\%$ Instruction } & Intercept & 35.88 & 3.36 & 946 & 10.69 & $<0.001$ & \\
\hline & Day's \% instruction** & -6.61 & 1.99 & 946 & -3.32 & $<0.001$ & -0.22 \\
\hline & Usual \% instruction* & -16.13 & 7.61 & 75 & -2.12 & 0.04 & -0.49 \\
\hline & Start date & -0.01 & 0.01 & 75 & -0.82 & 0.41 & \\
\hline & Day of study* & -0.57 & 0.12 & 946 & -4.74 & $<0.001$ & -0.31 \\
\hline Parent & Intercept & 35.09 & 3.39 & 1106 & 10.34 & $<0.001$ & \\
\hline \multirow[t]{4}{*}{ Stress } & Day's parent stress & -0.40 & 0.26 & 1106 & -1.54 & 0.12 & \\
\hline & Usual parent stress & -0.56 & 0.97 & 78 & -0.58 & 0.56 & \\
\hline & Start date & -0.01 & 0.01 & 78 & -0.87 & 0.39 & \\
\hline & Day of study* & -0.56 & 0.11 & 1106 & -5.10 & $<0.001$ & -0.31 \\
\hline Child & Intercept & 35.06 & 3.30 & 1106 & 10.63 & $<0.001$ & \\
\hline \multirow[t]{4}{*}{ Mood } & Day's mood* & 0.64 & 0.29 & 1106 & 2.21 & 0.03 & 0.13 \\
\hline & Usual mood & 2.98 & 1.57 & 78 & 1.89 & 0.06 & \\
\hline & Start date & -0.01 & 0.01 & 78 & -0.94 & 0.35 & \\
\hline & Day of study* & -0.55 & 0.11 & 1106 & -4.97 & $<0.001$ & -0.30 \\
\hline Child & Intercept & 35.88 & 3.29 & 994 & 10.89 & $<0.001$ & \\
\hline \multirow[t]{4}{*}{ Sleep } & $\begin{array}{l}\text { Previous night's sleep + } \\
\text { same day's nap }\end{array}$ & 0.85 & 0.49 & 994 & 1.74 & 0.08 & \\
\hline & Usual sleep & 0.38 & 1.76 & 76 & 0.22 & 0.83 & \\
\hline & Start date & -0.01 & 0.01 & 76 & -1.30 & 0.20 & \\
\hline & Day of study* & -0.55 & 0.12 & 994 & -4.65 & $<0.001$ & -0.29 \\
\hline
\end{tabular}




\section{FLUCTUATIONS IN PERSISTENCE}

Figure 2. Prototypical (black line) and person-specific (light gray lines) within-person associations between brushing time and daily a. percent praise, b. percent instruction, c. child's mood (on scale of 0 [extremely bad] to 10 [extremely good]), d. child's sleep (in hours), and e. parent stress (0 [not stressed at all] to 10 [extremely stressed]).

a.

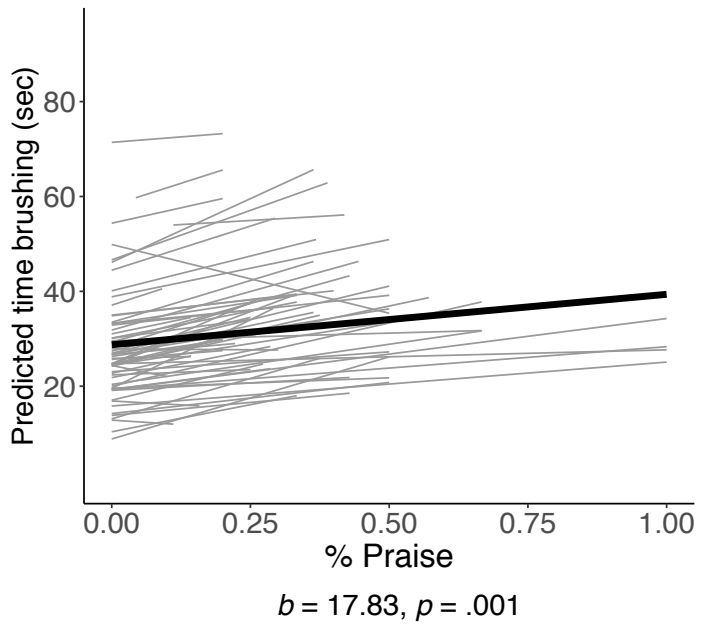

c.

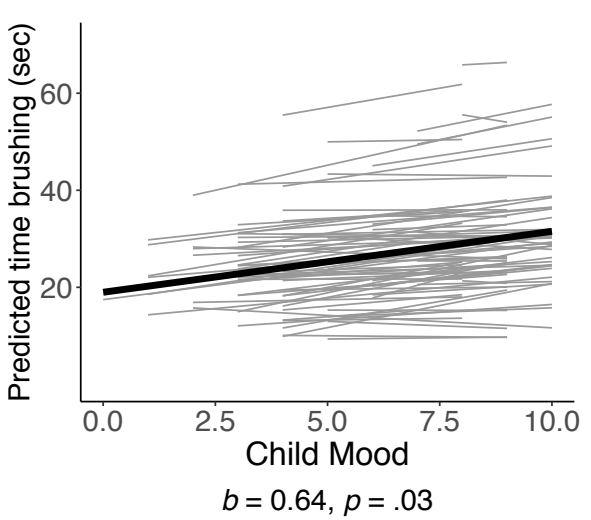

d. b.

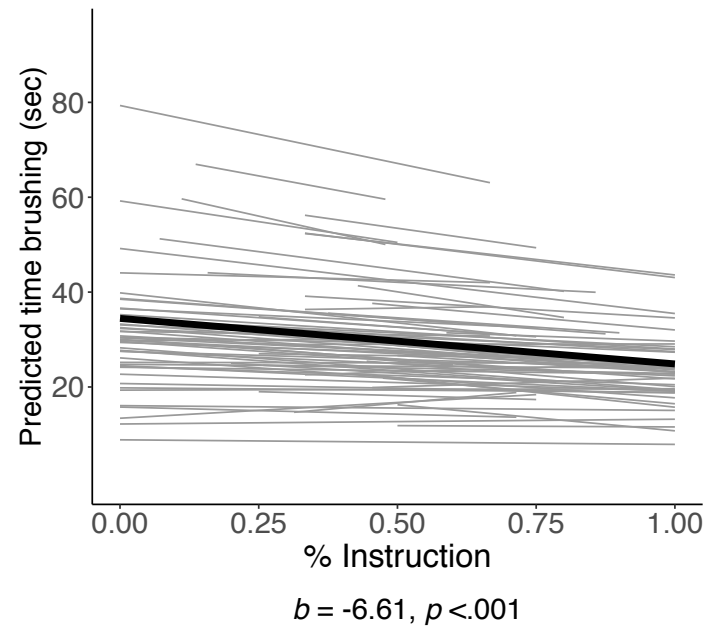

e.

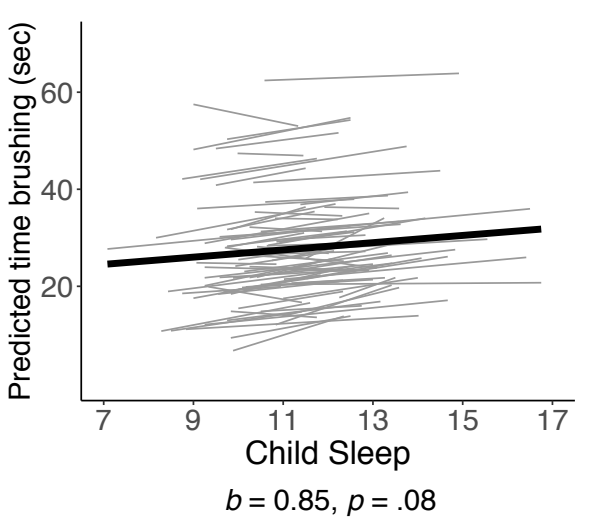

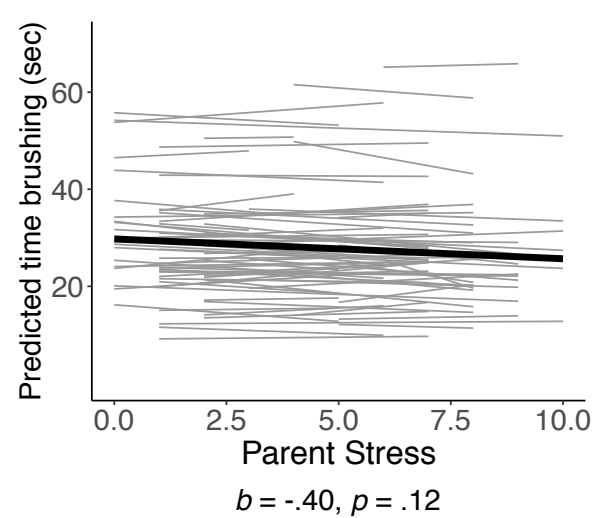


Table 2. Individual differences in brushing sensitivity. Correlations are shown between demographics (age, gender, socioeconomic status (SES), and parent perceived stress (PSS)) and standardized $\beta$ 's from models relating brushing to each predictor variable, controlling for day of the study. *uncorrected $p<.05, * *$ uncorrected $p<.01$. Bolded values survive FDR correction.

\begin{tabular}{|c|c|c|c|c|c|c|c|c|}
\hline & 1 & 2 & 3 & 4 & 5 & 6 & 7 & 8 \\
\hline \multicolumn{9}{|l|}{ 1. Age } \\
\hline 2. Gender & 0.15 & & & & & & & \\
\hline 3. SES & 0.01 & -0.05 & & & & & & \\
\hline 4. PSS & 0.00 & 0.04 & -0.06 & & & & & \\
\hline 5. Sleep sensitivity & -0.12 & 0.14 & -0.07 & 0.08 & & & & \\
\hline 6. Mood sensitivity & -0.10 & -0.01 & -0.02 & $-0.25^{*}$ & 0.21 & & & \\
\hline 7. Parent stress sensitivity & 0.04 & 0.02 & 0.10 & -0.08 & -0.12 & $-0.45 * *$ & & \\
\hline 8. \% Praise sensitivity & -0.21 & -0.02 & -0.05 & -0.01 & 0.01 & -0.12 & $0.26^{*}$ & \\
\hline 9. \% Instruction sensitivity & -0.01 & -0.01 & -0.06 & -0.14 & -0.12 & 0.22 & $-0.26^{*}$ & $-0.53 * *$ \\
\hline
\end{tabular}


Supplemental Materials

Daily fluctuations in young children's persistence 


\section{Contents}

Table SM 1. Multilevel models predicting brushing time including outlier subject................3

SM Table 2. Summary of daily measure administration. .................................

SM Table 3. Parent speech coding scheme with means and frequencies. $\ldots \ldots \ldots \ldots \ldots \ldots \ldots \ldots . . . .5$

SM Table 4. Correlations amongst parent talk measure intraindividual means. ..................6

SM Table 5. Variability in brushing time, percent praise, percent instruction, parent stress, child mood, and child sleep. ...............................................................

SM table 6 . Within-child variability in relationships among predictor variables. ...............8

SM Table 7. Correlation matrix of demographics and average brushing and predictor variables....9

SM Table 8. Correlation matrix of demographics and coefficient of variation of brushing and

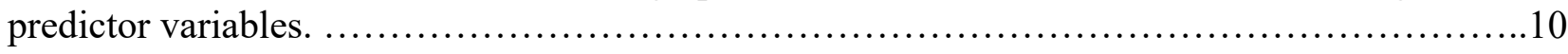

SM Table 9. Individual differences in brushing sensitivity without outlier values...............11

SM Table 10. Multilevel interaction models predicting toothbrushing by study start date........12

SM Table 11. Multilevel model predicting brushing time with all four predictor variables........13

SM Table 12. Multilevel model predicting time brushing with the average of parent daily measures of stress and mood.

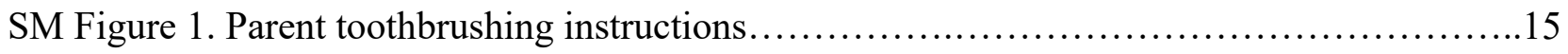

SM Figure 2. Prototypical (black line) and person-specific (light gray lines) within-person associations between parent stress and parent mood. 
Table SM 1. Multilevel models predicting brushing time including outlier subject. Estimates are not standardized. $* p<.05, * *$ FDR corrected $p<.05$ for within-child factors and between-child factors separately.

\begin{tabular}{|c|c|c|c|c|c|c|c|}
\hline & & Estimate & $S E$ & $\mathrm{df}$ & $t$ & $\underline{p}$ & $d$ \\
\hline \multirow[t]{5}{*}{$\%$ Praise } & Intercept & 40.94 & 5.91 & 813 & 6.93 & $<0.001$ & \\
\hline & Day's \% praise* & 12.60 & 5.25 & 813 & 2.40 & 0.02 & 0.17 \\
\hline & Usual \% praise & -60.82 & 34.40 & 61 & -1.77 & 0.08 & \\
\hline & Start date & -0.01 & 0.01 & 61 & -0.68 & 0.50 & \\
\hline & Day of study* & -0.72 & 0.22 & 813 & -3.30 & 0.001 & -0.23 \\
\hline \multicolumn{2}{|c|}{$\%$ Instruction Intercept } & 36.45 & 4.82 & 960 & 7.56 & $<0.001$ & \\
\hline & Day's \% instruction** & -6.84 & 2.38 & 960 & -2.87 & 0.004 & -0.19 \\
\hline & Usual \% instruction & -8.82 & 10.79 & 76 & -0.82 & 0.42 & \\
\hline & Start date & 0.00 & 0.01 & 76 & 0.00 & 1.00 & \\
\hline & Day of study* & -0.76 & 0.19 & 960 & -4.11 & $<0.001$ & -0.27 \\
\hline Parent & Intercept & 35.58 & 4.01 & 1120 & 8.86 & $<0.001$ & \\
\hline \multirow[t]{4}{*}{ Stress } & Day's parent stress & -0.05 & 0.42 & 1120 & -0.12 & 0.90 & \\
\hline & Usual parent stress & -0.38 & 1.14 & 79 & -0.33 & 0.74 & \\
\hline & Start date & -0.00 & 0.01 & 79 & -0.22 & 0.83 & \\
\hline & Day of study* & -0.69 & 0.15 & 1120 & -4.62 & $<0.001$ & -0.28 \\
\hline Child & Intercept & 36.73 & 4.64 & 1120 & 7.92 & $<0.001$ & \\
\hline \multirow[t]{4}{*}{ Mood } & Day's mood & 0.61 & 0.33 & 1120 & 1.86 & 0.06 & \\
\hline & Usual mood & 1.65 & 2.19 & 79 & 0.75 & 0.45 & \\
\hline & Start date & -0.01 & 0.01 & 79 & -0.44 & 0.66 & \\
\hline & Day of study* & -0.70 & 0.16 & 1120 & -4.40 & $<0.001$ & -0.26 \\
\hline Child & Intercept & 35.79 & 3.97 & 1006 & 9.01 & $<0.001$ & \\
\hline \multirow[t]{4}{*}{ Sleep } & $\begin{array}{l}\text { Previous night's sleep + } \\
\text { same day's nap }\end{array}$ & 0.57 & 0.59 & 1006 & 0.97 & 0.33 & \\
\hline & Usual sleep & 0.11 & 2.09 & 77 & 0.05 & 0.96 & \\
\hline & Start date & -0.01 & 0.01 & 77 & -0.58 & 0.57 & \\
\hline & Day of study* & -0.62 & 0.13 & 1006 & -4.91 & $<0.001$ & -0.31 \\
\hline
\end{tabular}


SM Table 2. Summary of daily measure administration. Time administered represents time that text messages prompts were sent to fill out surveys.

\begin{tabular}{|lll|}
\hline Measures & Time administered & Format \\
\hline Persistence (time brushing) & $8: 30 \mathrm{pm}$ & Video \\
\hline Parent talk & $8: 30 \mathrm{pm}$ & Video \\
\hline Parent stress & $8: 30 \mathrm{pm}$ & Parent report \\
\hline Child mood & $8: 30 \mathrm{pm}$ & Parent report \\
\hline Sleep duration & $8: 00 \mathrm{am} / 8: 30 \mathrm{pm}$ & Parent report \\
\hline
\end{tabular}


SM Table 3. Parent speech coding scheme with means and frequencies. Means are from intraindividual means. Frequency is the total occurrences across all nights and subjects. Any talk not directed towards child or in another language was coded as NA.

\begin{tabular}{|c|c|c|c|c|c|}
\hline Behavioral Code & Definition & \multicolumn{2}{|c|}{ Example } & M (sd) & Frequency \\
\hline Distraction & $\begin{array}{l}\text { Parent talk } \\
\text { intended to } \\
\text { distract child } \\
\text { from brushing. } \\
\text { Includes aspects } \\
\text { of pretend play }\end{array}$ & \multicolumn{2}{|c|}{$\begin{array}{l}\text { Singing, reading a book, } \\
\text { counting, pretend play } \\
\text { "Can you get lightning } \\
\text { McQueen?" }\end{array}$} & $0.41(1.10)$ & 442 \\
\hline \multirow[t]{3}{*}{ Praise } & \multirow{3}{*}{$\begin{array}{l}\text { Parent praise } \\
\text { including person, } \\
\text { process, and } \\
\text { other praise }\end{array}$} & Other & "Very good" & \multirow[t]{3}{*}{$0.78(1.08)$} & \multirow{3}{*}{$\begin{array}{l}\text { Total: } 833 \\
\text { Other: } 462 \\
\text { Process: } 349 \\
\text { Person: } 32\end{array}$} \\
\hline & & Process & "Good job" & & \\
\hline & & Person & $\begin{array}{l}\text { "You're good at } \\
\text { brushing" }\end{array}$ & & \\
\hline Instruction & $\begin{array}{l}\text { Parent tells child } \\
\text { what to do either } \\
\text { as a statement or } \\
\text { a question. }\end{array}$ & \multicolumn{2}{|c|}{$\begin{array}{l}\text { "Did you get the tops?"; } \\
\text { "Get the back"; "Finish } \\
\text { brushing". }\end{array}$} & 4.04(3.47) & 4587 \\
\hline Other & $\begin{array}{l}\text { Any other off } \\
\text { topic content or } \\
\text { comment that } \\
\text { doesn't fit into } \\
\text { the above } \\
\text { categories. }\end{array}$ & \multicolumn{2}{|c|}{$\begin{array}{l}\text { "Are you ready to } \\
\text { brush?", "How's the } \\
\text { brushing going?", } \\
\text { "everything OK?", [child's } \\
\text { name], "yeah"” }\end{array}$} & $2.97(3.20)$ & 3273 \\
\hline
\end{tabular}


SM Table 4. Correlations amongst parent talk measure intraindividual means. Averages are from raw count data.

\begin{tabular}{llll}
\hline & 1 & 2 & 3 \\
\hline 1. Praise Avg & & & \\
2 Instruction Avg & $0.68^{* *}$ & & \\
3. Distraction Avg & $0.62 * *$ & $0.27 *$ & \\
4. Other Avg & $0.63 * *$ & $0.74 * *$ & $0.31 *$ \\
\hline
\end{tabular}

*FDR corrected $p<.05, * *$ FDR corrected $p<.01$ 
SM Table 5. Variability in brushing time, percent praise, percent instruction, parent stress, child mood, and child sleep.

\begin{tabular}{clcccc}
\hline & & Mean & SD & Min & Max \\
\hline Intraindividual & Brushing & 28.39 & 13.56 & 4.55 & 74.07 \\
& \% Praise & 0.08 & 0.08 & 0.00 & 0.33 \\
& \% Instruction & 0.53 & 0.20 & 0.00 & 1.00 \\
& Parent stress & 3.89 & 1.53 & 1.31 & 7.56 \\
& Child mood & 7.29 & 0.91 & 4.75 & 9.19 \\
& Sleep & 11.41 & 0.82 & 9.85 & 14.02 \\
\hline Intraindividual & Brushing & 0.51 & 0.21 & 0.19 & 1.12 \\
coefficient & \% Praise & 1.69 & 0.89 & 0.43 & 4.00 \\
& \% Instruction & 0.58 & 0.47 & 0.00 & 2.83 \\
& Parent stress & 0.50 & 0.25 & 0.09 & 1.44 \\
& Child mood & 0.23 & 0.10 & 0.05 & 0.59 \\
& Sleep & 0.08 & 0.03 & 0.03 & 0.22 \\
& & & & & \\
\hline
\end{tabular}


SM table 6. Within-child variability in relationships among predictor variables. Showing within (wn) and between (bn) child relationships amongst predictor variables. Models are run with the rows predicting variables in each column. We did not run any models predicting prior night's sleep. Gray cells are significant at $p<.05$. Bolded cells are significant at FDR corrected $p<.05$ (corrected for within- and between-subjects $p$ values separately).

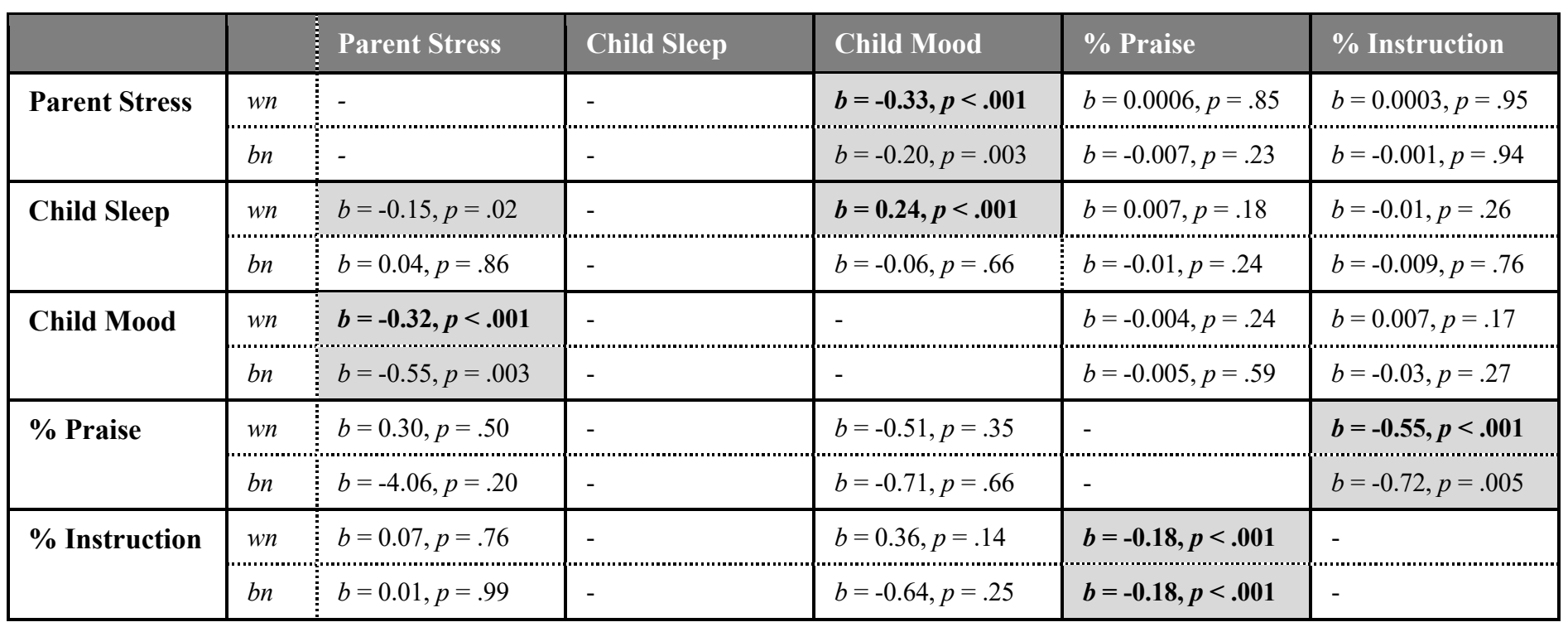


SM Table 7. Correlation matrix of demographics and average brushing and predictor variables. Demographic measures include age, gender, socioeconomic status (SES), and perceived parent stress (PSS), which were measured before the EMA portion of the study. Bolded values survive FDR correction for multiple comparisons. *uncorrected $p<.05$, ** uncorrected $p<.01$

\begin{tabular}{|c|c|c|c|c|c|c|c|c|c|}
\hline & 1 & 2 & 3 & 4 & 5 & 6 & 7 & 8 & 9 \\
\hline \multicolumn{10}{|l|}{ 1. Age } \\
\hline 2. Gender & 0.15 & & & & & & & & \\
\hline 3. SES & 0.01 & -0.05 & & & & & & & \\
\hline 4. PSS & 0.00 & 0.04 & -0.06 & & & & & & \\
\hline 5. Brushing Avg & 0.00 & -0.20 & 0.07 & -0.04 & & & & & \\
\hline 6. Sleep Avg & -0.21 & -0.04 & 0.04 & -0.04 & 0.00 & & & & \\
\hline 7. Child mood Avg & 0.09 & -0.04 & -0.12 & 0.05 & $0.24 *$ & -0.04 & & & \\
\hline 8. Parent stress Avg & -0.04 & -0.06 & 0.00 & $0.51 * *$ & -0.06 & 0.04 & $-0.32 * *$ & & \\
\hline 9. \% Praise Avg & -0.11 & -0.01 & 0.17 & -0.17 & 0.05 & -0.12 & 0.02 & -0.11 & \\
\hline 10. \% Instruction Avg & -0.15 & -0.14 & -0.15 & -0.12 & -0.16 & 0.01 & -0.13 & 0.00 & -0.18 \\
\hline
\end{tabular}


SM Table 8. Correlation matrix of demographics and coefficient of variation of brushing and predictor variables. Demographic measures include age, gender, socioeconomic status (SES), and perceived parent stress (PSS), which were measured before the EMA portion of the study. Cov $=$ coefficient of variation. Bolded values survive FDR correction. * uncorrected $p<.05, * *$ uncorrected $p$ $<.01$

\begin{tabular}{|c|c|c|c|c|c|c|c|c|c|}
\hline & 1 & 2 & 3 & 4 & 5 & 6 & 7 & 8 & 9 \\
\hline \multicolumn{10}{|l|}{ 1. Age } \\
\hline 2. Gender & 0.15 & & & & & & & & \\
\hline 3. SES & 0.01 & -0.05 & & & & & & & \\
\hline 4. PSS & 0.00 & 0.04 & -0.06 & & & & & & \\
\hline 5. Brushing Cov & -0.18 & 0.20 & $-0.43 * *$ & -0.03 & & & & & \\
\hline 6. Sleep Cov & 0.09 & $0.29 * *$ & -0.14 & $0.26^{*}$ & -0.11 & & & & \\
\hline 7. Child mood Cov & -0.07 & -0.07 & 0.06 & -0.06 & $0.23 *$ & 0.01 & & & \\
\hline 8. Parent stress Cov & 0.11 & 0.10 & 0.03 & $-0.38 * *$ & -0.02 & 0.08 & 0.08 & & \\
\hline 9. \% Praise Cov & -0.11 & 0.02 & -0.20 & 0.23 & 0.01 & 0.15 & 0.11 & -0.15 & \\
\hline 10. \% Instruction Cov & 0.07 & 0.08 & 0.11 & 0.02 & -0.09 & 0.00 & 0.07 & -0.05 & -0.04 \\
\hline
\end{tabular}


SM Table 9. Individual differences in brushing sensitivity without outlier values. Correlations are shown between demographics (age, gender, socioeconomic status (SES), and parent perceived stress (PSS)) and standardized $\beta$ 's from models relating brushing to each predictor variable, controlling for day of the study. Two outlying values removed for $\%$ instruction sensitivity and one for $\%$ praise sensitivity. *uncorrected $p<.05,{ }^{* *}$ uncorrected $p<.01$. Bolded values survive FDR correction.

\begin{tabular}{|c|c|c|c|c|c|c|c|c|}
\hline & 1 & 2 & 3 & 4 & 5 & 6 & 7 & 8 \\
\hline \multicolumn{9}{|l|}{ 1. Age } \\
\hline 2. Gender & 0.15 & & & & & & & \\
\hline 3. SES & 0.01 & -0.05 & & & & & & \\
\hline 4. PSS & 0.00 & 0.04 & -0.06 & & & & & \\
\hline 5. Sleep sensitivity & -0.12 & 0.14 & -0.07 & 0.08 & & & & \\
\hline 6. Mood sensitivity & -0.10 & -0.01 & -0.02 & $-0.25^{*}$ & 0.21 & & & \\
\hline 7. Parent stress sensitivity & 0.04 & 0.02 & 0.10 & -0.08 & -0.12 & $-0.45 * *$ & & \\
\hline 8. \% Praise sensitivity & $-0.29 *$ & 0.07 & -0.06 & -0.15 & 0.07 & -0.03 & 0.19 & \\
\hline 9. \% Direct Instruction sensitivity & 0.11 & -0.04 & -0.11 & -0.05 & $-0.25^{*}$ & 0.07 & -0.21 & $-0.43 * *$ \\
\hline
\end{tabular}


SM Table 10. Multilevel interaction models predicting toothbrushing by study start date. Estimates are not standardized. $* p<.05$.

\begin{tabular}{|c|c|c|c|c|c|c|c|}
\hline & & Estimate & $S E$ & df & $t$ & $p$ & $d$ \\
\hline \multirow[t]{6}{*}{$\%$ Praise } & Intercept & 38.37 & 4.08 & 798 & 9.40 & $<0.001$ & \\
\hline & Day's \% praise* & 27.83 & 11.91 & 798 & 2.34 & 0.02 & 0.17 \\
\hline & Usual \% praise & -13.21 & 24.61 & 60 & -0.54 & 0.59 & \\
\hline & Start date & -0.01 & 0.01 & 60 & -1.17 & 0.25 & \\
\hline & Day of study* & -0.55 & 0.14 & 798 & -3.92 & $<0.001$ & -0.28 \\
\hline & $\begin{array}{l}\text { Start date X Day's } \\
\% \text { praise }\end{array}$ & -0.03 & 0.03 & 798 & -0.94 & 0.35 & \\
\hline \multirow[t]{6}{*}{$\%$ Instruction } & Intercept & 35.48 & 3.42 & 945 & 10.36 & $<0.001$ & \\
\hline & Day's \% instruction & -4.37 & 4.06 & 945 & -1.08 & 0.28 & \\
\hline & Usual \% instruction* & -16.27 & 7.64 & 75 & -2.13 & 0.04 & -0.49 \\
\hline & Start date & -0.01 & 0.01 & 75 & -0.66 & 0.51 & \\
\hline & Day of study* & -0.57 & 0.12 & 945 & -4.77 & $<0.001$ & -0.31 \\
\hline & $\begin{array}{l}\text { Start date X Day's } \\
\% \text { instruction }\end{array}$ & -0.01 & 0.01 & 945 & -0.64 & 0.52 & \\
\hline Parent & Intercept & 35.10 & 3.39 & 1105 & 10.35 & $<0.001$ & \\
\hline \multirow[t]{5}{*}{ Stress } & Day's parent stress & -0.55 & 0.54 & 1105 & -1.01 & 0.31 & \\
\hline & Usual parent stress & -0.56 & 0.97 & 78 & -0.58 & 0.56 & \\
\hline & Start date & -0.01 & 0.01 & 78 & -0.87 & 0.39 & \\
\hline & Day of study* & -0.57 & 0.11 & 1105 & -5.11 & $<0.001$ & -0.31 \\
\hline & Start date X Day's stress & 0.00 & 0.00 & 1105 & 0.30 & 0.76 & \\
\hline Child & Intercept & 35.41 & 3.31 & 1105 & 10.70 & $<0.001$ & \\
\hline \multirow[t]{5}{*}{ Mood } & Day's mood* & 1.32 & 0.57 & 1105 & 2.31 & 0.02 & 0.14 \\
\hline & Usual mood & 2.97 & 1.57 & 78 & 1.89 & 0.06 & \\
\hline & Start date & -0.01 & 0.01 & 78 & -1.05 & 0.30 & \\
\hline & Day of study* & -0.55 & 0.11 & 1105 & -5.00 & $<0.001$ & -0.30 \\
\hline & Start date X Day's mood & -0.00 & 0.00 & 1105 & -1.32 & 0.19 & \\
\hline Child & Intercept & 35.89 & 3.29 & 993 & 10.89 & $<0.001$ & \\
\hline \multirow[t]{5}{*}{ Sleep } & $\begin{array}{l}\text { Previous night's sleep + } \\
\text { same day's nap }\end{array}$ & 0.70 & 1.25 & 993 & 0.56 & 0.58 & \\
\hline & Usual sleep & 0.38 & 1.76 & 76 & 0.22 & 0.83 & \\
\hline & Start date & -0.01 & 0.01 & 76 & -1.30 & 0.20 & \\
\hline & Day of study* & -0.55 & 0.12 & 993 & -4.65 & $<0.001$ & -0.29 \\
\hline & $\begin{array}{l}\text { Start date X Previous } \\
\text { night's sleep + same } \\
\text { day's nap }\end{array}$ & 0.00 & 0.00 & 993 & 0.13 & 0.90 & \\
\hline
\end{tabular}


SM Table 11. Multilevel model predicting brushing time with all four predictor variables. Estimates are not standardized. $* p<.05$

\begin{tabular}{lcccccc}
\hline & Estimate & $S E$ & df & $t$ & $p$ & $d$ \\
\hline \hline Intercept & 39.96 & 3.85 & 704 & 10.37 & $<0.001$ & \\
Day's \% praise* & 13.92 & 5.28 & 704 & 2.64 & 0.01 & 0.20 \\
Usual \% praise & -11.37 & 23.37 & 55 & -0.49 & 0.63 & \\
Day's \% instruction & -5.05 & 2.63 & 704 & -1.92 & 0.06 & \\
Usual \% instruction & -18.37 & 10.77 & 55 & -1.71 & 0.09 & \\
Day's parent stress & -0.24 & 0.44 & 704 & -0.55 & 0.58 & \\
Usual parent stress & 0.67 & 1.03 & 55 & 0.65 & 0.52 & \\
Day's mood* & 0.93 & 0.38 & 704 & 2.43 & 0.02 & 0.18 \\
Usual mood* & 4.89 & 1.92 & 55 & 2.55 & 0.01 & 0.69 \\
Previous night's sleep + & & & & & & \\
same day's nap & -0.12 & 0.59 & 704 & -0.20 & 0.84 & \\
Usual sleep & 1.62 & 1.87 & 55 & 0.87 & 0.39 & \\
Start date & -0.02 & 0.01 & 55 & -1.78 & 0.08 & \\
Day of study* & -0.61 & 0.15 & 704 & -4.03 & $<0.001$ & -0.30 \\
& & & & & & \\
\hline
\end{tabular}


SM Table 12. Multilevel model predicting time brushing with the average of parent daily measures of stress and mood. Estimates are not standardized. ${ }^{*} p<.05$

\begin{tabular}{clcccccc}
\hline & Estimate & $S E$ & df & $t$ & $p$ & $d$ \\
\hline \hline \multirow{2}{*}{ Parent avg } & Intercept & 35.24 & 3.37 & 1105 & 10.44 & $<0.001$ \\
stress + mood & Day's parent avg stress+mood & -0.01 & 0.62 & 1105 & -0.02 & 0.98 \\
& Usual parent avg stress+mood & 1.45 & 2.31 & 78 & 0.63 & 0.53 \\
& Start date & -0.01 & 0.01 & 78 & -0.96 & 0.34 & \\
& Day of study* & -0.55 & 0.11 & 1105 & -4.93 & $<0.001$ & -0.30 \\
& & & & & & \\
\hline
\end{tabular}




\section{SM Figure 1. Parent toothbrushing instructions}

How to collect toothbrushing data: Every night, record a video of your child brushing their teeth on your recording device. Have your child brush by themselves for as long as they can before you take over and finish the job. This is important! We want to see how long children brush their teeth by themselves each night. Look at the graphic below for more instructions (you can even print it out and hang it in the bathroom if that's helpful!):

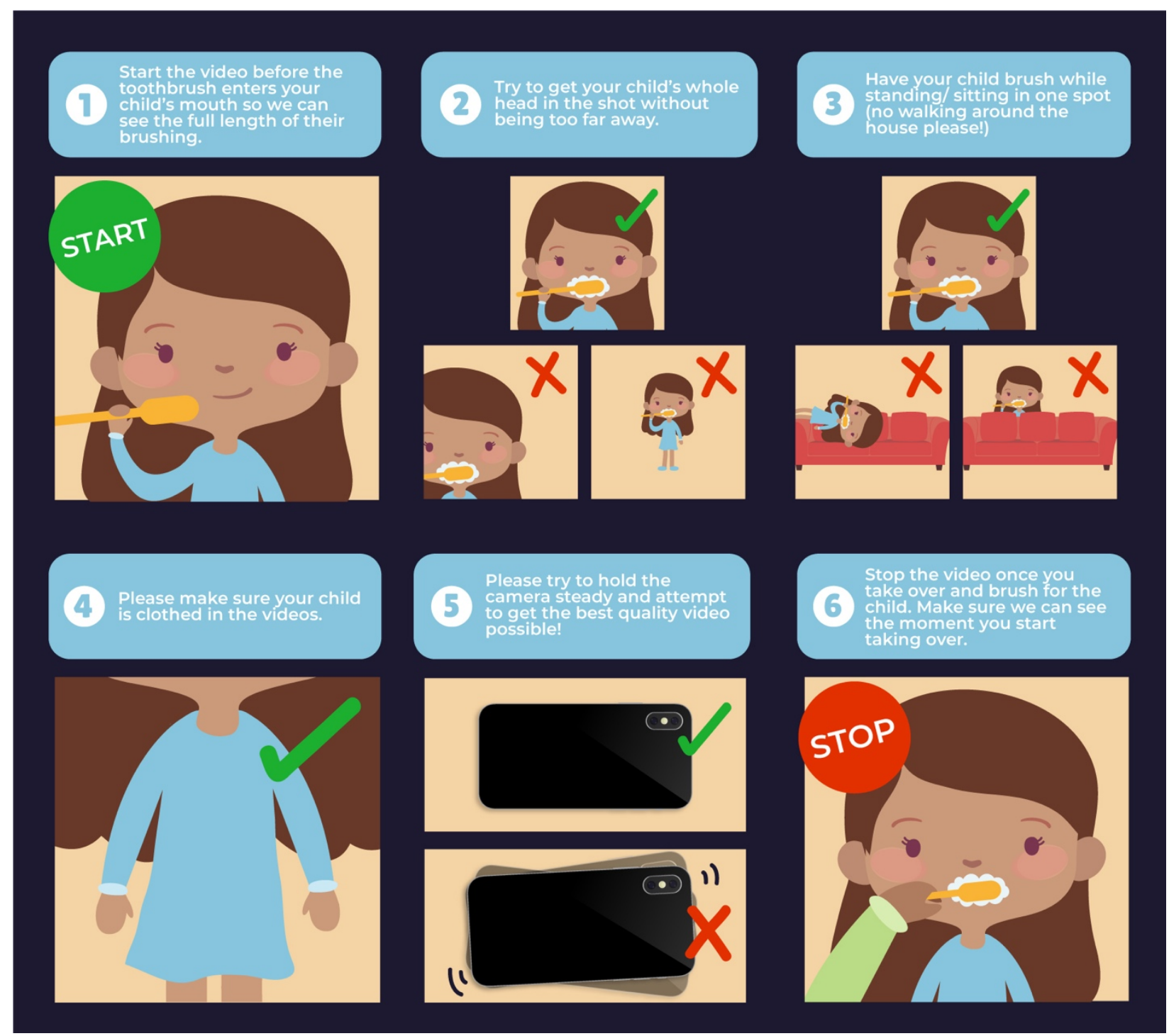

Frequently Asked Questions:

Question: My kid went to bed without brushing their teeth tonight, so I have no video. I tried to turn in the survey, but it won't let me submit without uploading any content. What do I do?

Answer: This happens! Please just upload a picture of something (that you are ok sharing with us) and write in the "are there any other things going on today" section what happened. For time brushing teeth, write in "0:25 AM." 
SM Figure 2. Prototypical (black line) and person-specific (light gray lines) within-person associations between parent stress and parent mood.

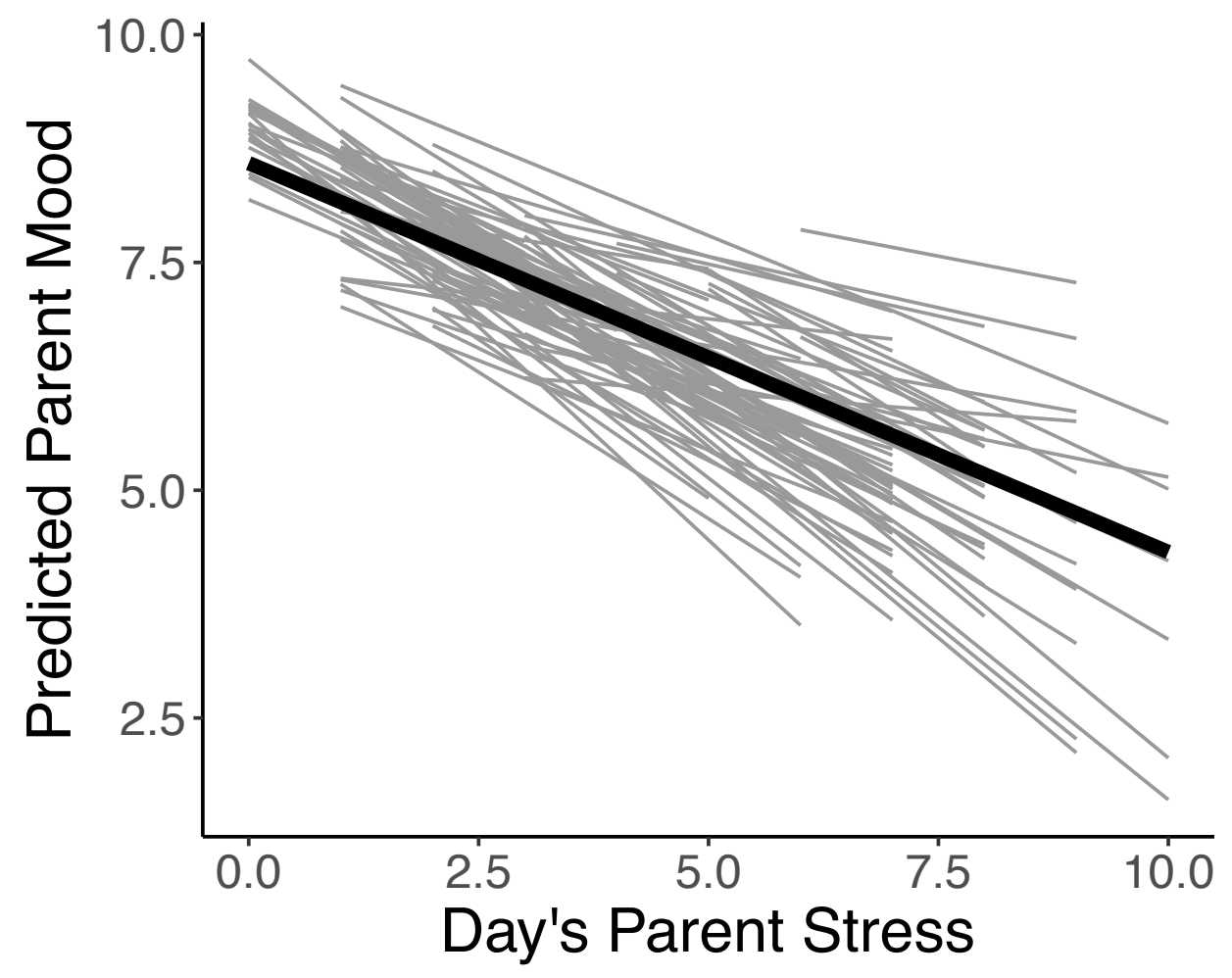

